
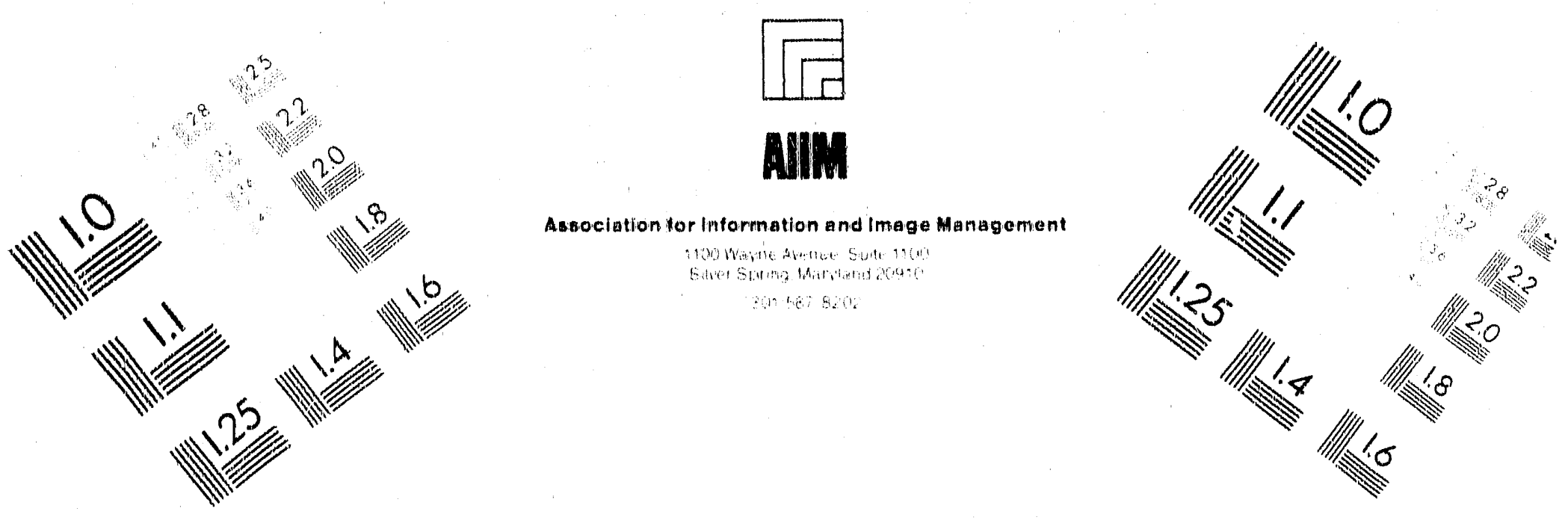

\title{
Centimeter
}

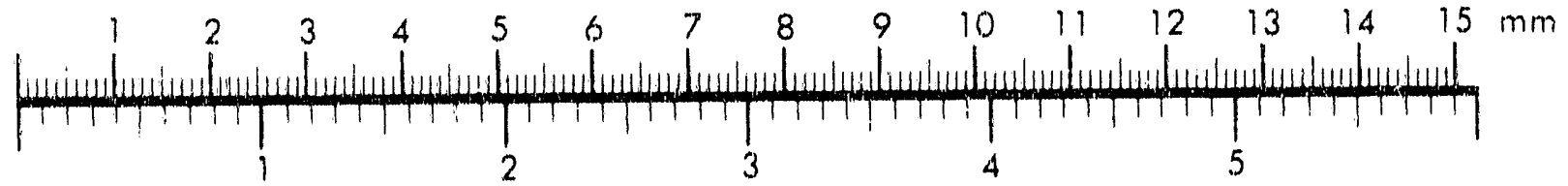
Inches
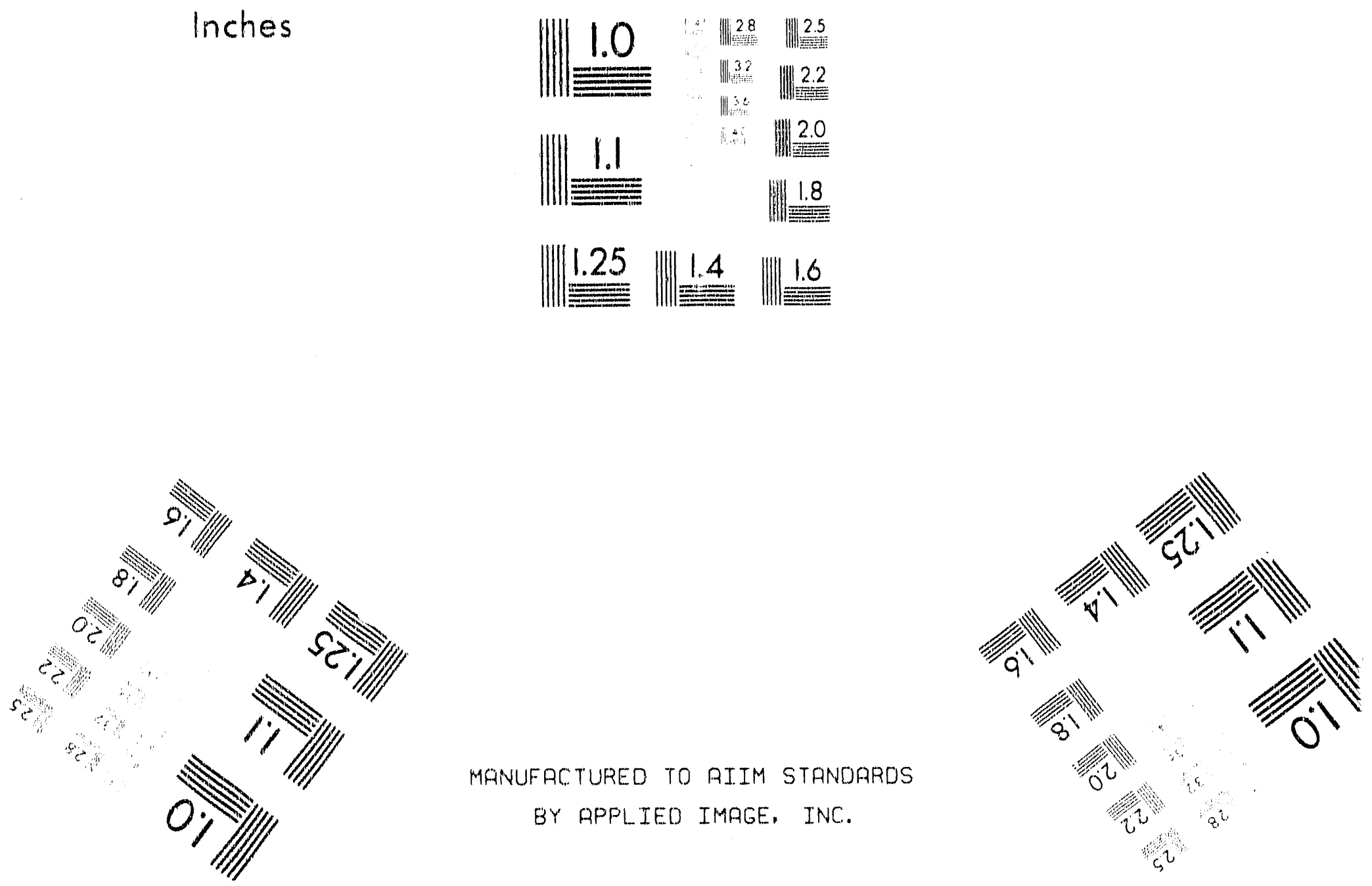

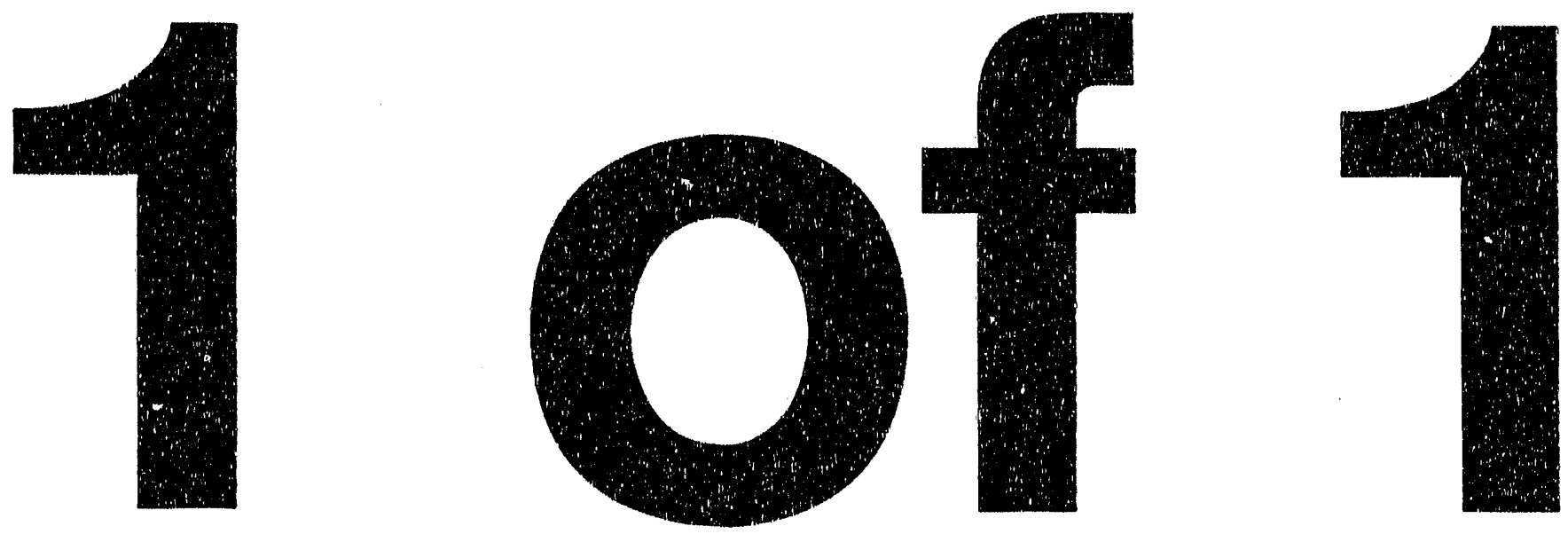


\section{AXIAL POWER MONITOR ROD ISSUED AND RESOLUTION FOR K-14.1 (U)}

by

T. C. Easterling

Westinghouse Savannah River Company

Savannah River Site

Aiken, South Carolina 29808

Received by OSTI

\author{
AUG? 01992
}

This report was prepared in connection with work done under Contract No. DE-AC09-89SR 18035 with the U.S. Department of Energy. By acceptance of this report, the publisher and/or recipient acknowledges the U.S. Government's right to retain a nonexclusive, royalty-free license in and to any copyright covering this report, along with the right to reproduce and to authorize others to reproduce all or part of the copyrighted report. 


\section{DISCLAIMER}

This report was prepared as an account of work sponsored by an agency of the United States Government. Neither the United States Government nor any agency thereof, nor any of their employees, makes any warranty, express or implied, or assumes any legal liability or responsibility for the accuracy, completeness, or usefulness of any information, apparatus, product, or process disclosed, or represents that its use would not infringe privately owned rights. Reference herein to any specific commercial product, process, or service by trade name, trademark, manufacturer, or otherwise does not necessarily constitute or imply its endorsement, recommendation, or favoring by the United States Government or any agency thereof. The views and opinions of authors expressed herein do not necessarily state or reflect those of the United States Government or any agency thereof.

This report has been reproduced directly from the best available copy.

Available to DOE and DOE contractors from the Office of Scientific and Technical Information, P.O. Box 62, Oak Ridge, TN 37831; prices available from (615) 576-8401, FTS 626-8401.

Available to the public from the National Techncial Information Service, U.S. Department of Commerce, 5285 Port Royal Rd., Springfield, VA 22161. 


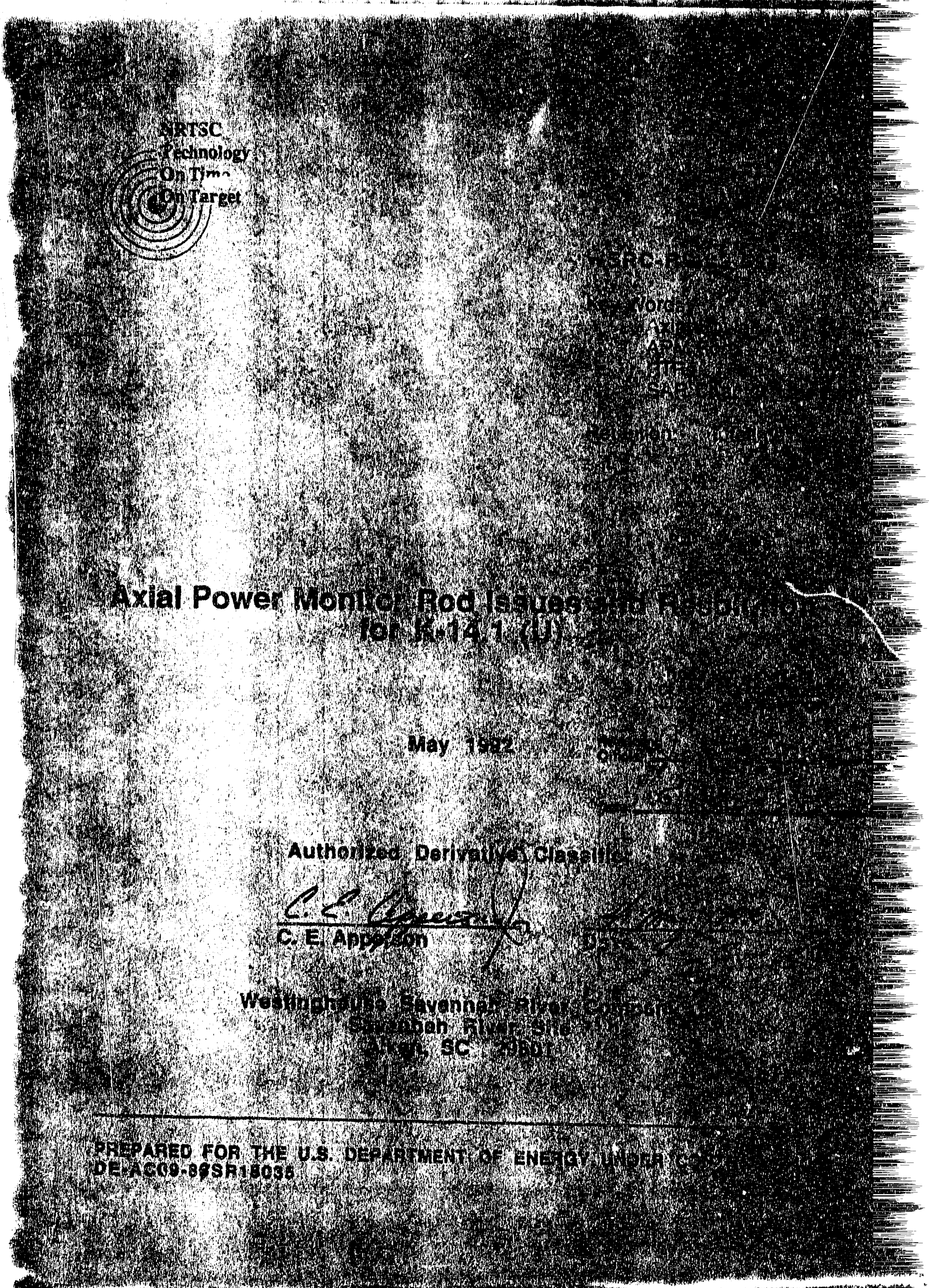


Document: WSRC-RP-92-594

Title: Axial Power Monitor Rod Issues and Resolution for K-14.1

\section{APPROVALS}
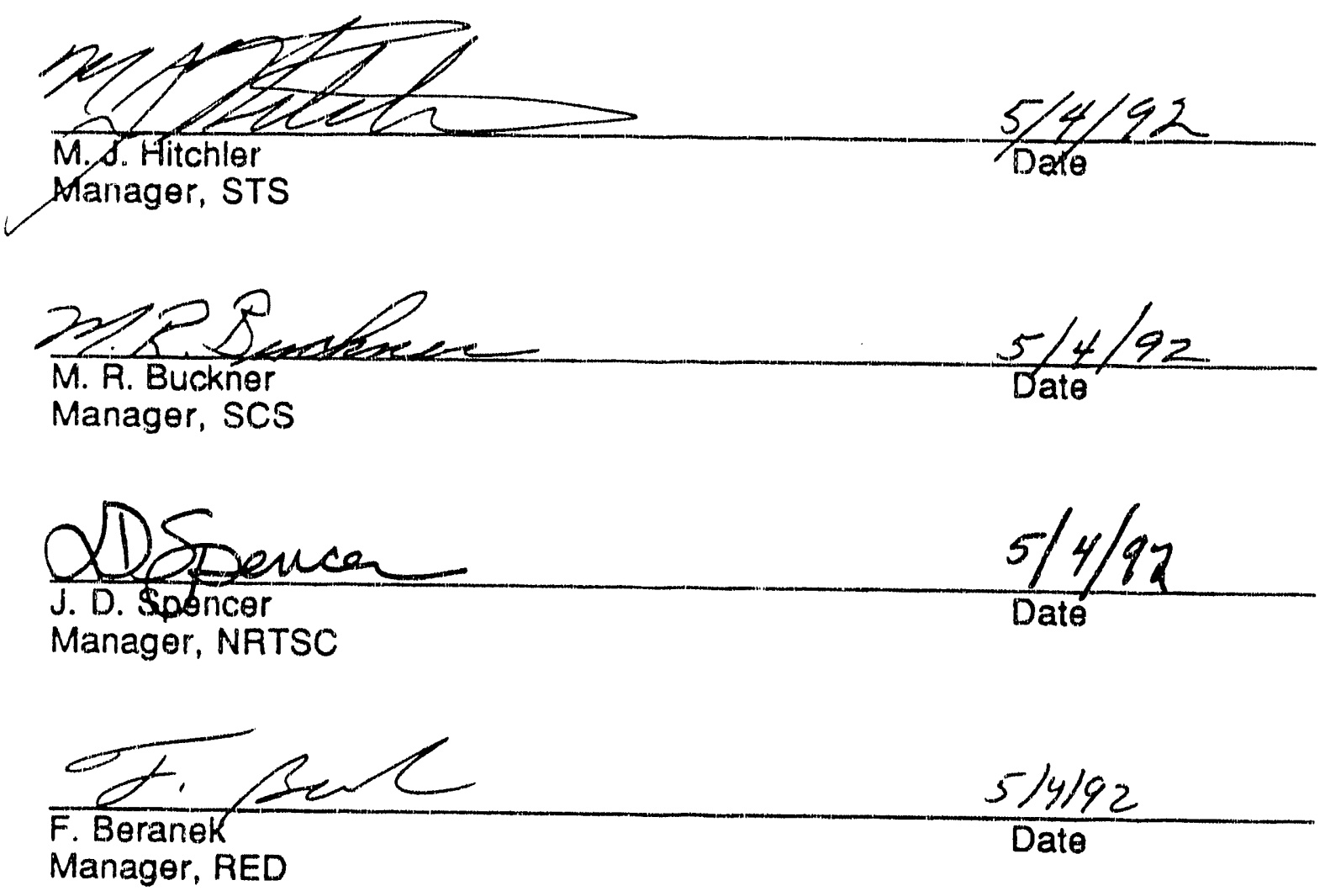
Manager, RED

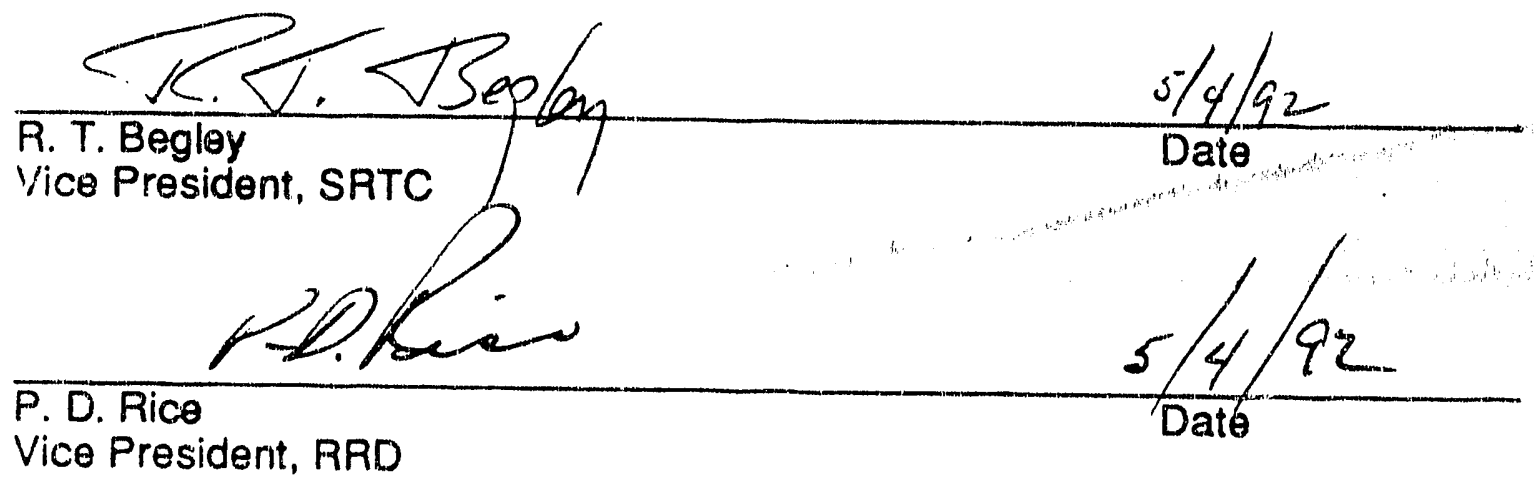

Vice President, RRD 
Document: WSRC-RP-92-594

Title: $\quad$ Axial Power Monitor Rod Issues and Resolution for K-14.1

TECHNICAL EDITORS

T. C. Easterling

C. C. Fields

N. T. Hightower, III

L. A. Wooten

CONTRIBUTING AUTHORS
S. K. Andre
C. E. Apperson
M. H. Bailey
D. L. Bell
G. H. Clare
S. L. Collins
W. D. Croft
T. B. Edwards
G. T. Geiger
S. P. Harris
J. L. Lietzow
R. W. MoCulloch (Deita-M)
A. F. MaFarlane
H. W. Randolph
R. L. Reed
C. P. Reevé
S. M. Revolinski
H. T. Sessions
E. P. $\operatorname{Shin} \theta$
T. A. Smith
C. L. Sossman
J. J. Taylor
J. H. Weber 


\section{TABLE OF CONTENTS}

EXECUTIVE SUMMARY 1

1.0 INTRODUCTION 3

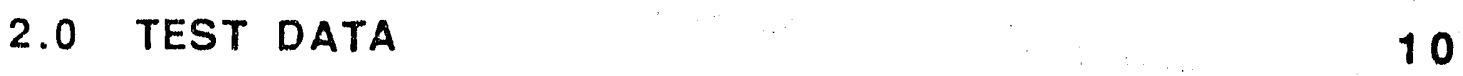

3.0 CHANNEL STATISTICAL ANALYSIS 22

4.0 STATISTICAL ANALYSIS 22

5.0 SAFETY ANALYSIS 30

6.0 OPERATIONAL CONSIDERATIONS 31

7.0 PROCEDURE CHANGES 32

8.0 STARTUP TEST CHANGES 33

9.0 CONCLUSION 35 


\section{LIST OF TABLES AND FIGURES}

FIGURE $1-1$

FIGURE 1-2

FIGURE 1-3

FIGURE 1.4

FIGURE 1-5

FIGURE 2-1

FIGURE 2-2

FIGURE 2-3

FIGURE 2-4

FIGURE 2.5

FIGURE $2+6$

FIGURE 2.7

FIGURE: $2-8$

FIGURE 2-9

FIGURE 2-10

FIGURE 2-11

FIGURE 2-12

FIGURE 2-13

FIGURE 2-14

FIGURE 2-15

FIGURE 4-1

FIGURE 4-2

FIGURE 4-3

TABLE 4-1

TABLE 4-2

TABLE 4-3

TABLE 4-4
REACTOP APM ROD LOCATIONS

SENSOR LOCATIONS

APM ROD AXIAL CROSS SECTION

APM ROD LONGITUDINAL CROSS-SECTION

THIMBLE ORIENTATION

JOULE HEATING TEST

JOULE HEATING TEST

1984 APM DATA - C AREA

1984 APM DATA - C AREA

DATA FROM K AREA

DATA FROM K AREA

RTR (RAW DATA)

RTR (RAW DATA)

RTR CONFIDENCE INTERVAL

APM ROD 39 JOULE DATA

RTR (RAW DATA)

RTR CONFIDENCE INTERVAL

RTR (RAW DATA)

RTR (RAW DATA)

EFFECT OF HEATED SPACER WITH NO FLOW AND CABLE HEATING

CALIBRATION DATA FROM APM ROD 3

CALIBRATION DATA FROM APM ROD 8

CALIBRATION DATA FROM APM ROD 6

TYPICAL APM DETECTOR RESPONSE SUMMARY OF ROOF-TOP-RATIO UNCERTAINTIES 25 SUMMARY OF ROOF-TOP-RATIO UNCERTAINTIES 26 SUMMARY OF ROOF-TOP-RATIO UNCERTAINTIES 27 


\section{EXECUTIVE SUMMARY}

A recent concern arose over the treatment of uncertainty associated with the $\mathrm{K}$ Reactor axial power monitors (APMs). There are nine axial power monitor rods located at various positions in the K-Reactor core. By comparing the output of one sensur near the top of the rod to the output of another sensor near the bottom of the rod, the relative ratio of the neutron flux from the top to the bottom of the core can be determined. This ratio is called the roof-top-ratio RTR) and is the output of a top sensor (Sensor 2) divided by the output of a botrom sensor (Sensor 6).

The RTR is important to the safety analyses because when the RTR is maintained within certain ranges, the se'verity of reactivity transients is limited. At low powers the Technical Specifications do not require any limits to be placed on the RTR. At a specified intermediate power level the range is set as an RTR reading between 0.80 and 1.2. As power is increased to a higher level the RTR range is tightened to 0.90 and 1.1 .

There are uncertainties associated with the equipment's ability to measure the true roof top ratio. It was determined recently that sufficient uncertainty was not accounted for either in reactor operation or in the safery arialyses. The concern about uncertainty was addressed for three separate issues. One issue dealt with the linear response of the sensors for power ranges planned for K-Reactor operation. The second issue dealt with overall uncertainty in the RTR channel. The third issue dealt with apparent large ranges in confidence bands for the RTR at low reactor powers as represented by original vendor data. Plots of sparse vendor data indicated unacceptably large uncertainties in RTR would have to be accounted for at the power ranges planned for K-Reactor operation. These concerns were brought to management's attention through the existing procedures $i$. I notification, irrespective of their potential impact on the restart schedule.

Analyses have been completed to resolve the APM issues described above, and work is progressing to take the needed steps to change operational procedures, Control Computer software, and the startup test program to assure the RTR uncertainties used in the safety analyses remain valid. The uncertainty in RTR, which is different for each APM rod, was accounted for by repeating the safety analyses at $30 \%$ of historical power ( $720 \mathrm{MW}$; limiting case) for the affected reactivity transients using RTR ranges consistent with the current Technical Sprecification linits and calculational uncertainties. A range of 0.66 to 1.46 is now allowed for in the safety analyses, while the Technical Specifictisu is have been left unchanged. An uncertainty band of $\pm<10 \%$ has been determined by testing recently performed by the vendor on a rod of K-Reactor design and by tests conducted on the actual rods in the K-Reactor tank. The data that has been obtained indicates very little non-linearity exists in the power range of interest for K-Reactor operation. The small non-linear effects that do exist are now accounted for in the overall channel uncertainty values determined from the tests performed by both the vendor and at K-Reactor and studies on the rest of the channel. These tests have eliminated the unacceptably large uncertainty in RTR 
from the original vendor data at low powers. The unacceptably large uncertainty was assessed to be an artifact of: 1) only three data points being fit in the unacceptably laige uncertainty range from the original vendor data, 2) the method of fitting the data, and 3) an error in the recording of the zero-power sensor readings on the test rig.

The path forward is to incorporate the appropriate bias factors in the Control Computer. Work will proceed to modify the Power Ascension Program in order to assess the validity of the biases. This will require calibrating the APMs with the Traveling Wire Flux Monitor (TWFM) data and modifying the Control Computer software to accept the biases that are determined. In addition, the analog to digital converter (ADC) will be rescaled to decrease the uncertainty in the channel that determines the RTR. This work is being incorporated into the power ascension testing already planned.

In conclusion, the appropriate RTR measurement uncertainty has been included in the safety analyses, and power ascension can proceed with confidence that the axial power profile can be maintained within acceptable ranges. 


\section{INTRODUCTION}

This report describes resolution of concerns over the axial power monitors (APMs) as they are used to measure the roof-top-ratio (RTR) which is a measure of relative power between the top and the bottom of the core. The APMs are shown in Figures 1-1 through Figure 1-5. Figure 1-1 shows the location of the rods as they appear in the K-Reactor tank. Figure 1-2 shows the individual sensors along the axial length of the rods. A detailed description of an APM rod is shown in Figures 1-3 through 1-5.

The power density throughout the K-Reactor core is not homogeneous but varies from regions of relatively high to relatively low power. These different power density regions exist due to varying fuel densities, poison buildup, neutron reflectors, and rod insertion configurations. The reactor's three dimensional power distributions are represented with radial and axial profiles.

Imbalances in power, either radially or axially, can have adverse effects on safety margins.

In order to specify limits that preserve the safety envelope and to implement a standard method of control, several ratios have been developed to characterize the core's radial and axial power shapes within the Technical Specifications for K-Reactor (Reference 1). One measure is the roo top-ratio (RTR) which is used to characterize single peaked flux shapes and is defined as the ratio of the power density approximately $1 / 4$ of the way from the top of the core (sensor 2) to approximately $3 / 4$ of the way from the top of the core (sensor 6 ). Depending on the core's power shape the RTR will be greater than, less than, or equal to one.

The APMs are self calibrating gamma thermometers (SCGT) that were manufactured by the Delta-M Corporation. They are used to measure the axial power profile. There are nine APM rods in the reactor (three per gang) that are inserted into one-inch positions. These rods contain seven sensors along their axial length. Using the information from the APMs, reactor operators use partial length rods to control the RTR within Technical Specification limits.

Technical Specification 3.2.2 sets two ranges for the RTRs depencing on power level. These ranges are $0.80-1.20$ from the Instrument Shape Applicability Limit (ISAL) to the Power Shape Applicability Limit (PSAL) and 0.90 - 1.10 from PSAL to full power. ISAL is defined as a $7^{\circ} \mathrm{C} \triangle T(\approx 270 \mathrm{MW})$ and PSAL is defined as a $13^{\circ} \mathrm{C} \Delta T(\approx 580 \mathrm{MW})$. The RTRs on the individual APMs must be maintained within these bounds to preserve the safety analyses.

Physics parameters used in the safety analyses are computed for certain ranges of RTR values. Thie safety analyses that use these physics parameters are valid only for those specific ranges of RTr: values. Therefore, an increase or decrease in the maximum and minimum RTR values defined in the Technical Specifications could cause physics parameters used in the safety analyses, such as reactivity addition values, to increase. An increase in the reactivity 
addition values used in the safety analyses could be severe enough to violate the current safety analyses.

The APM rods were initially designed and procured when operating levels for the SRS reactors were around $2400 \mathrm{MW}$. Since that time, the planned reactor operating power has been reduced to $720 \mathrm{MW}$. The Savannah River Technology Center (SRTC) performed testing to determine if the rods responded linearly at the low power ranges expected during reactor operation. During the test program in March, it became apparent that the uncertainty in measuring the RTR may be larger than that assumed in the physics analysis. Subsequent review of the physics data showed that a $2.2 \%$ uncertainty in the Control Computer reading for RTR was accommodated.

All of the origina! vendor data was analyzed for the RTR measurement. The data showed good measurement accuracy at high power levels in the APM rods (high millivolt [mV]), but as the power in the rods decreased, the measurement accuracy decreased. This was a cause of concern because it appeared to result in an unacceptably large RTR uncertainty.

Action was taken to determine the total channel uncertainty in the Control Computer channel. This channel uncertainty includes the sensor and all associated component uncertainties and needs to be accounted for in comparing measured RTR values to the Technical Specification limits.

The path forward was to determine what corrective actions needed to be taken to assure that the safety envelope is always maintained. This was done through testing, data gathering, statistical analysis of the data, statistical uncertainty analysis of the processing channels, and changes to procedures and control Computer software. 
Figure 1-1

Reactor APM locations

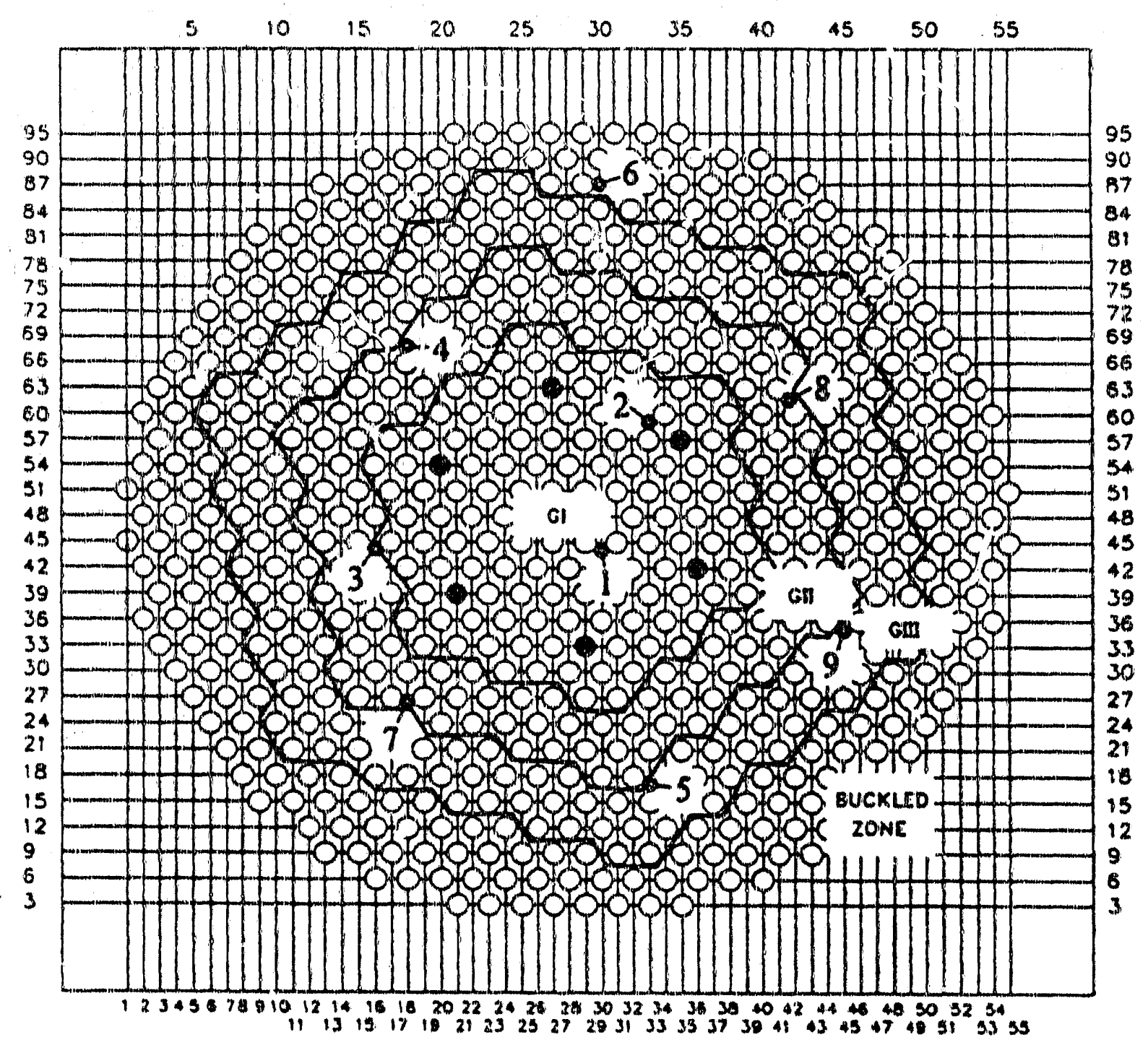

Cl. Gll. etc. Gong Designotion. 
WSRC-RP-92-594

Figure 1.2

Sensor Locations

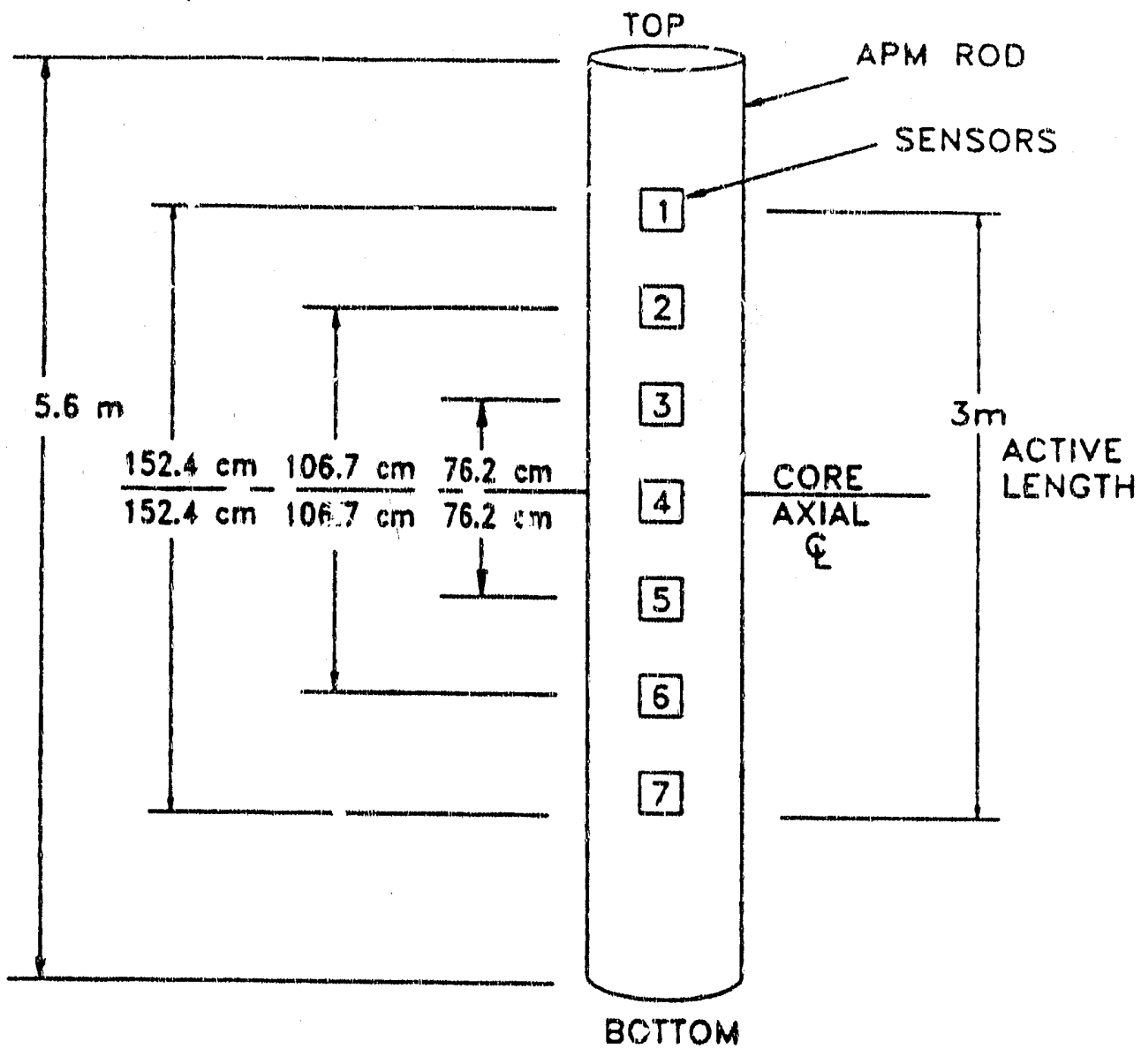


WSRC-RP-92-594

Figure 1-3

APM Rod Axial Cross Section
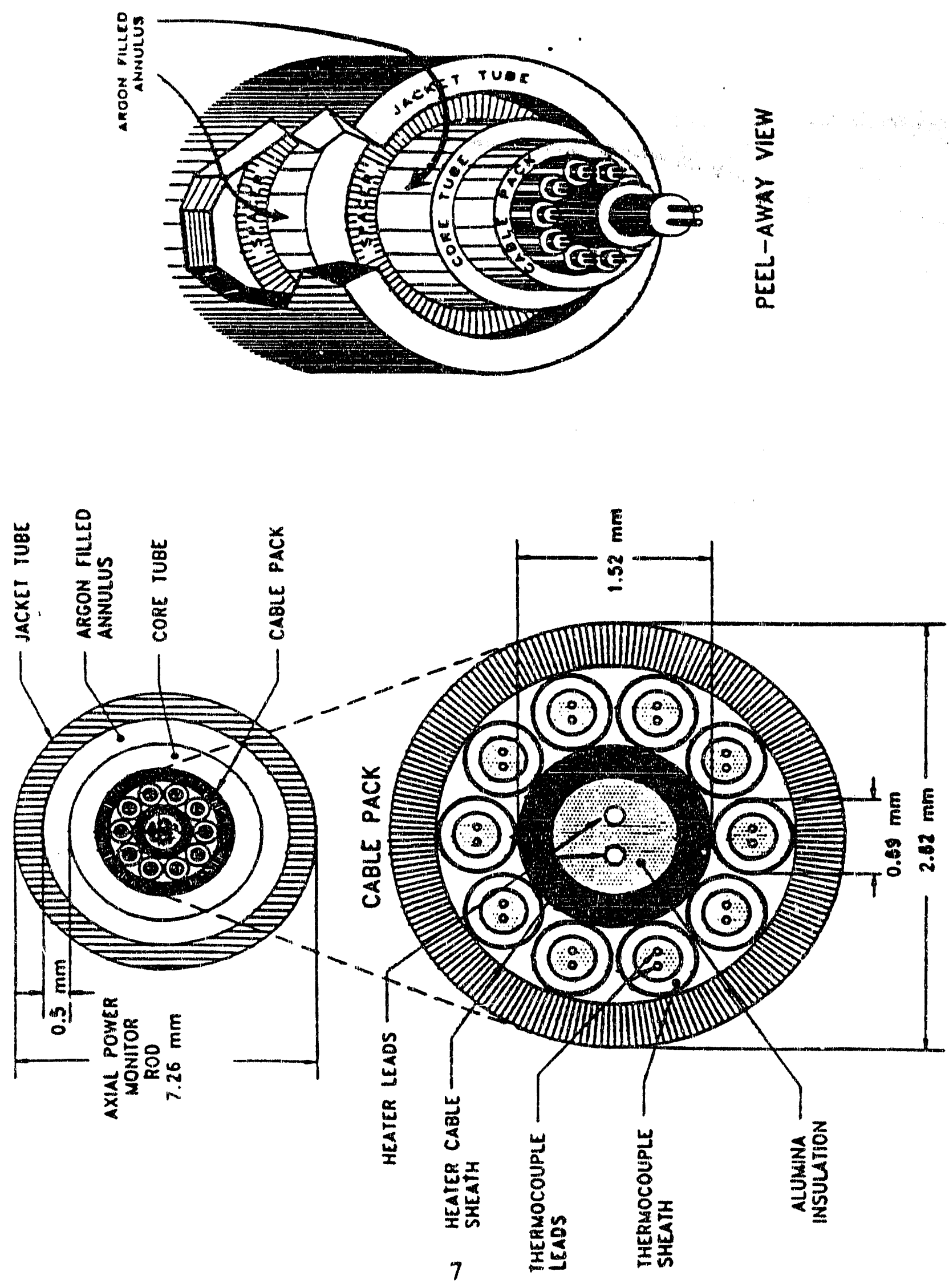
Figure $\mathbf{1 . 4}$

APM Rod Longitudinal Cross-Section

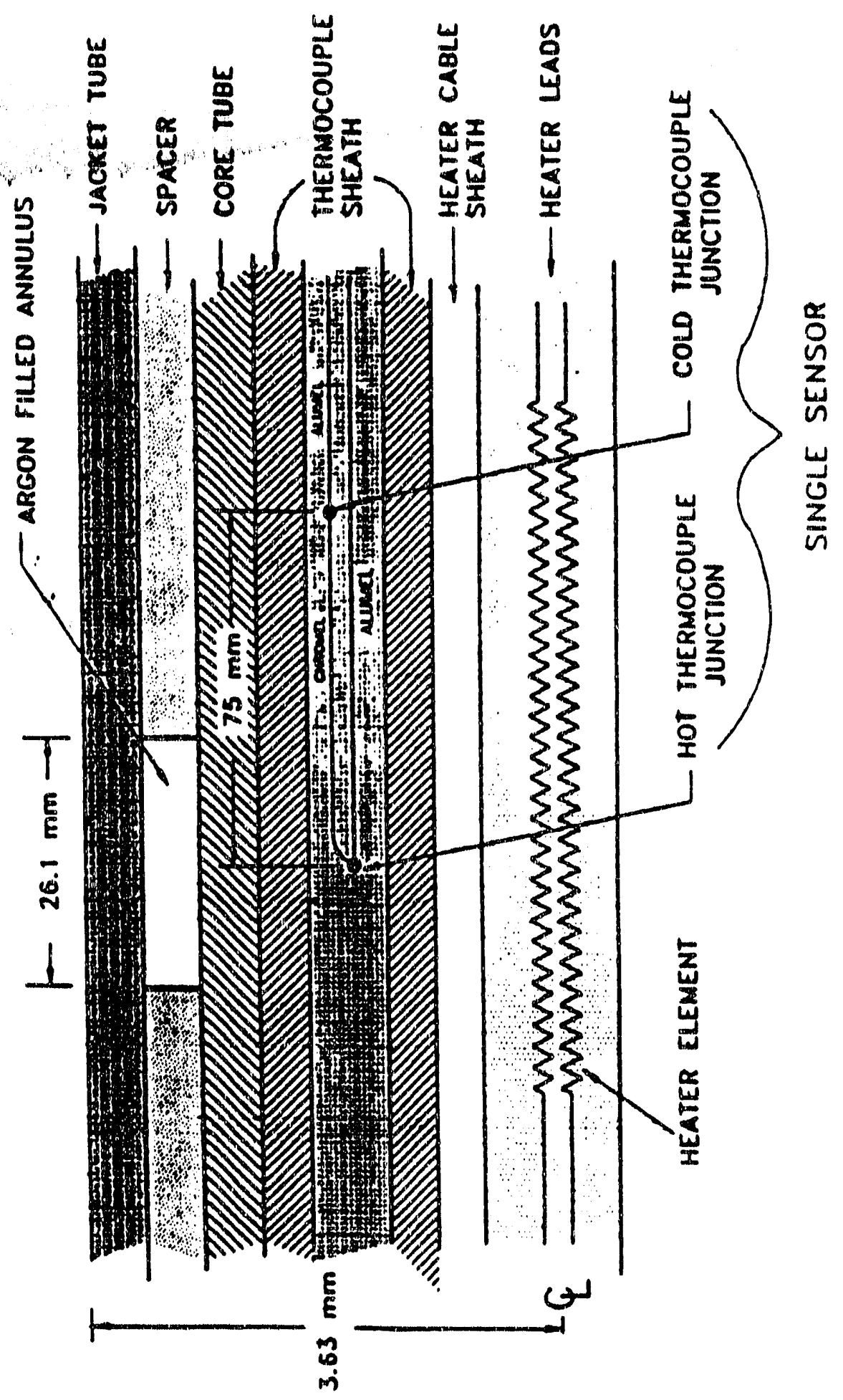


WSRC-RP-92-594

Figure $1-5$

Thimble Orientation

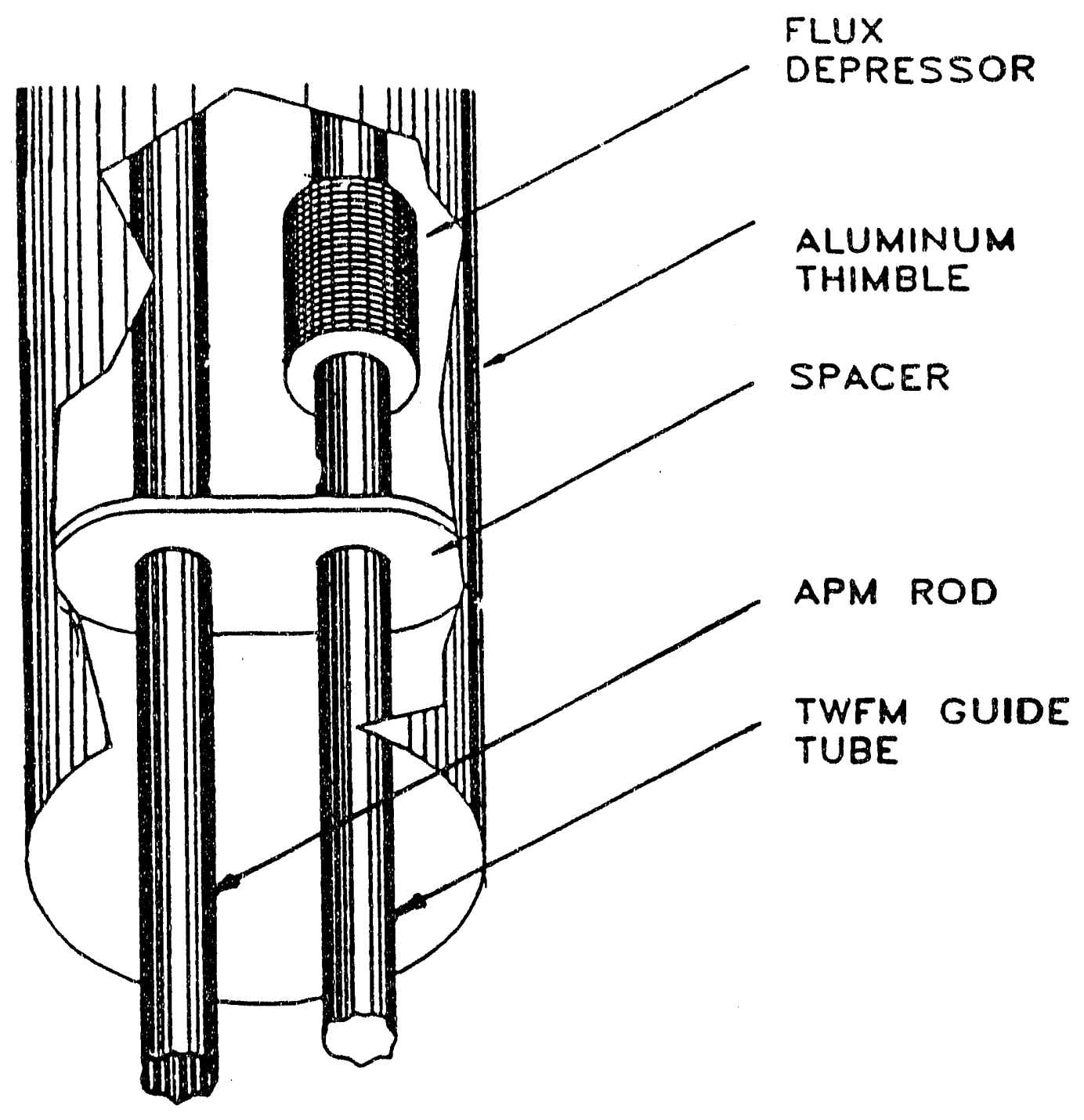




\subsection{TEST DATA}

\section{SRS Data}

Two current K-Reactor type SCGT APM rods were evaluated via in-core testing in 1984. One was evaluated in K-Reactor and one was evaluated in C-Reactor. Most of the data acquisition for these rods was at $100 \%$ reactor power $(2400$ MW). However, during the first startup after the current K-Reactor type APM rod was installed in C.Reactor, data was recorded at and below $75 \mathrm{MW}$. This data shows that the SCGT APM rod can monitor the reactor axial power shape from below $75 \mathrm{MW}$ to $2400 \mathrm{MW}$. No TWFM data was taken below $60 \%$ power for comparison or to determine uncertainties.

The 1984 data demonstrated that the current K-Reactor type APM rod had adequate sensitivity to monitor the reactor at $300 \mathrm{MW}$. The next concern was linearity of the APM response. The vendor supplied test data showed linear APM response at power densities from 0.5 to 6 watts/gram from simulated gamma heating. However, startup tests planned for K-Reactor required the APM rods to be operated as low as 0.05 watts per gram. To demonstrate linearity in this region, tests were performed on the nine SCGT APM rods installed in K-Reactor using the rod's internal heaters. The internal heaters simulate reactor gamma heating. The power to this heater can be varied to simulate gamma heating from 0 to 1.9 watts/gram. The data from these tests were gathered by both the APM data acquisition system (DAS) and $t, \theta_{\text {e }}$ Control Computer.

Results of the K-Reactor internal heater test showed linear operation of the SCGT APM rods from 0.0 to 1.9 watts/gram. Although each sensor demonstrated a linear response, the slopes were different for each sensor. This difference is primarily due to deviations in the segmented internal heater output. To prove this, it was decided to perform a Joule heating test on a spare SCGT APM rod. Joule heating of the entire rod more accurately simulates the reactor garnma heating but this test cannot be performed on the APMs installed in KReactor. The SCGT APM must be removed from the one-inch reactor instrument thimble position to perform this test.

A test was performed on spare APM rod $\# 003$ using a configured test apparatus. The one-inch reactor instrument thimble was cut away and the TWFM guide tube removed to allow access to each end of the SCGT assembly to connect the DC power supply. A section of the instrument thimble was used as the water jacket to simulate reactor conditions.

Results of these tests again showed linear response of each sensor. They also showed significantly less difference in the slope of each detector. This proved that the internal heater was a major contributor to differences in the slopes of the SCGT APM sensor responses in K-Reactor. Internal heater tests were repeated on the APM rods in K-Reactor and the Joule heating test apparatus to obtain statistical information.

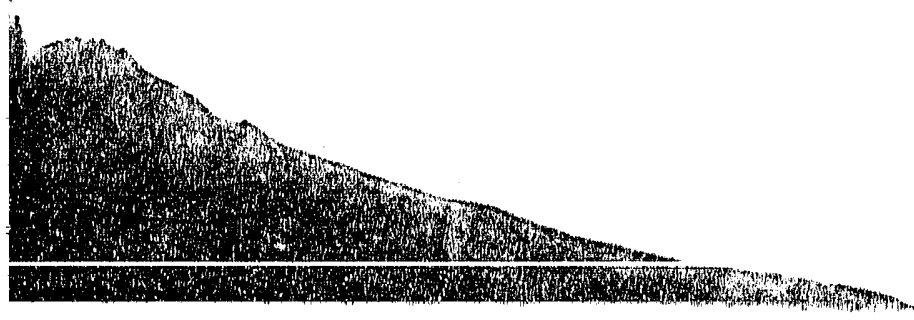


WSRC-RP-92-594

\section{Delta-M Data}

Tests were conducted on an APM rod (\#39) at the vendor's facility in Oak Ridge, Tenriessee. In these tests, several parameters were varied to determine the response of the rods at the powers anticipated during reactor operations. The parameters included:

1. type of heating - Joule or internal cable

2. surrounding conditions - flow speed and direction

3. spacer heating effects

The goal of these tests was to determine the uncertainty associated with signals from the rods and the uncertainty associated with the roof-top-ratio (RTR).

The test rod was placed in a jacket (nominal 1-inch ID) through which water flowed. The water through the jacket was metered and the direction of flow could be changed. Electrical connections were made to facilitate Joule heating and internal cable heating of the rod. The signal (in $\mathrm{mV}$ ) from each of the differential thermocouples was measured and the power input to each sensor was determined from the current input and the resistance of the sensor heater. In general, a set of data was collected by incrementally varying the rod power from low power, to high power, then to low power again. At each step, five data points were collected. In this fashion, measurement uncertainty and hysterisis effects could be assessed.

\section{- Delta-M Cable Heating Data}

The current to the internal cable heater in the rod was varied to yield power densities of 0.0 watts/gram to 2.6 watts/gram corresponding to sensor signals of $0.0 \mathrm{mV}$ to about $4 \mathrm{mV}$ respectively. The flow conditions for the test were $0.2 \mathrm{ft}$ per second (fps) flowing from sensor 7 to sensor 1. This is referred to as forward flow and corresponds to flow from the bottom to the top of the reactor.

Data scatter for individual sensors was very small throughout the power range studied as evidenced in Figure 2-7, which shows the data for Sensor 2 as well as the least squares linear and quadratic curve fits drawn through the data. Clearly, the response is very linear. Any effect of scatter is, of course, magnified when calculating the RTR as the signal from Sensor 2 is divided by that of Sensor 6 . The RTR data is shown in Figure $2-8$ as a function of the power density. For the most part, the RTR is less than unity, indicating that the signal from Sensor 6 is greater than that of Sensor 2. Thus, a bias exists.

This bias can be corrected in the following fashion. For a group of data, determine the average values of the Sensor 2 and Sensor 6 signals. With these values, the difference between the averages is found and divided by the value of Sensor 2 to obtain a relative error. This can then be applied to all Sensor 6 values within the group to obtain modified Sensor 6 values. The RTR based on the modified Sensor 6 value is also shown in Figure 2-8. Clearly, the 
corrected RTR value is very near unity, thereby confirming the ability of the modification method to correct the signal bias.

The confidence intervals for the predicted (from the individual sensor quadratics) uncorrected RTR values are displayed in Figure 2-9. These show that the RTR confidence interval value has a value for less than 5 percent for sensor signals in excess of about $0.2 \mathrm{mV}$.

\section{- Delta-M Joule Heating}

Tests similar to those described above were conducted using Joule heating rather than cable teating. The signals from Sensor 2 are shown in Figure $2-10$ along with the best fit linear and quadratic curves through the data. Again the data appears well behaved and nearly linear throughout the test range. The RTR data generated from the data is displayed in Figure 2-11 for both the uncorrected and corrected average RTR values. As before, the corrected values of RTR are very near unity. The scatter in the uncorrected data is due to hysterisis effects. Confidence intervals for the uncorrected, predicted RTR values are shown in Figure 2-12 and remain below 10 percent for sensor signal value in excess of about $0.25 \mathrm{mV}$.

\section{- Delta-M Flow Direction and Spacer Influence}

Scoping tests were conducted to assess the impact of an external heat source/sink exterior to the rod in the neighborhood of the Sensor 6 cold junction. Furthermore, the influence of the flow direction was also assessed. In Figure 2-13, the effects of a spacer (with a spacer and without a spacer) and flow direction (forward flow (FF), reverse flow (RF), and no flow (NF)) on RTR values are shown. The total variation between all cases is about 13 percert (RTR values from 0.91 to 1.03). The highest RTR values are found for the case when there is no flow and no spacer (the cold junction of Sensor 6 is most insulated). On the other hand, the minimum RTR values are found with forward flow with a spacer (a heat sink is in the neighborhood of the cold junction).

\section{- Delta-M Spacer Heating}

In the reactor, the spacer will be heated by gamma radiation. To model this, a resistance temperature detector (RTD) was epoxied into a small-diameter (about 0.085 inch) hole drilled into a prototypic spacer and located approximately $1 / 16$ inch from the rod surface. This RTD was heated by electric current to provide, effectively, a point source of heat embedded within the spacer. Thus, this test does not model the actual reactor situation in a completely prototypic fashion as the spacer is not uniformly heated throughout as it would be in the reactor.

RTR results are shown in Figure 2-14 for various rod power densities and spacer (RTD) powers. When the spacer power is high relative to the rod power density, the impact on the uncorrected RTR (based on raw signals) can be substantial. With no spacer heat input, the RTR values are typically about 0.91 
in this case. However, with a RTD heat input of about 9 watts, the RTR values become about 1.11. Thus, in this case, the RTR has been changed by a factor of 22 percent. For cases within no flow and spacer heating, the RTR consistently rises (by as much as about 30 percent for spacer poweis between 0 and $9 \mathrm{~W}$ ) with increased spacer power as shown in Figure 2-15.

\section{Summary of SRS and Delta-M Test Data}

The APM rods have been rigorously tested in the range of power expected for $K-$ Reactor operation. While the uncertainty in the sensor output for a given set of exterior conditions is low, the flow direction and the presence of a heated spacer near Sensor 6 does contribute to significant overall uncertainties including bias in the APM measurament of the RTR. The uncertainty in RTR exhibited by the Delta-M data and K-RE:actor tests is similar. Signal uncertainties at low rod powers reported previously by the vendor have been greatly reduced by taking more data in the range of interest and by a more careful test setup. In particular the very large uncertainties seen in the original Delta-M data have been discredited. Other uncertainties in the RTR as determined by the APM rods may be present in the reactor due to the unknown degree of spacer heating in the reactor. 
Figure 2.1

Joule Heating Test

APM Rod Serial \#003
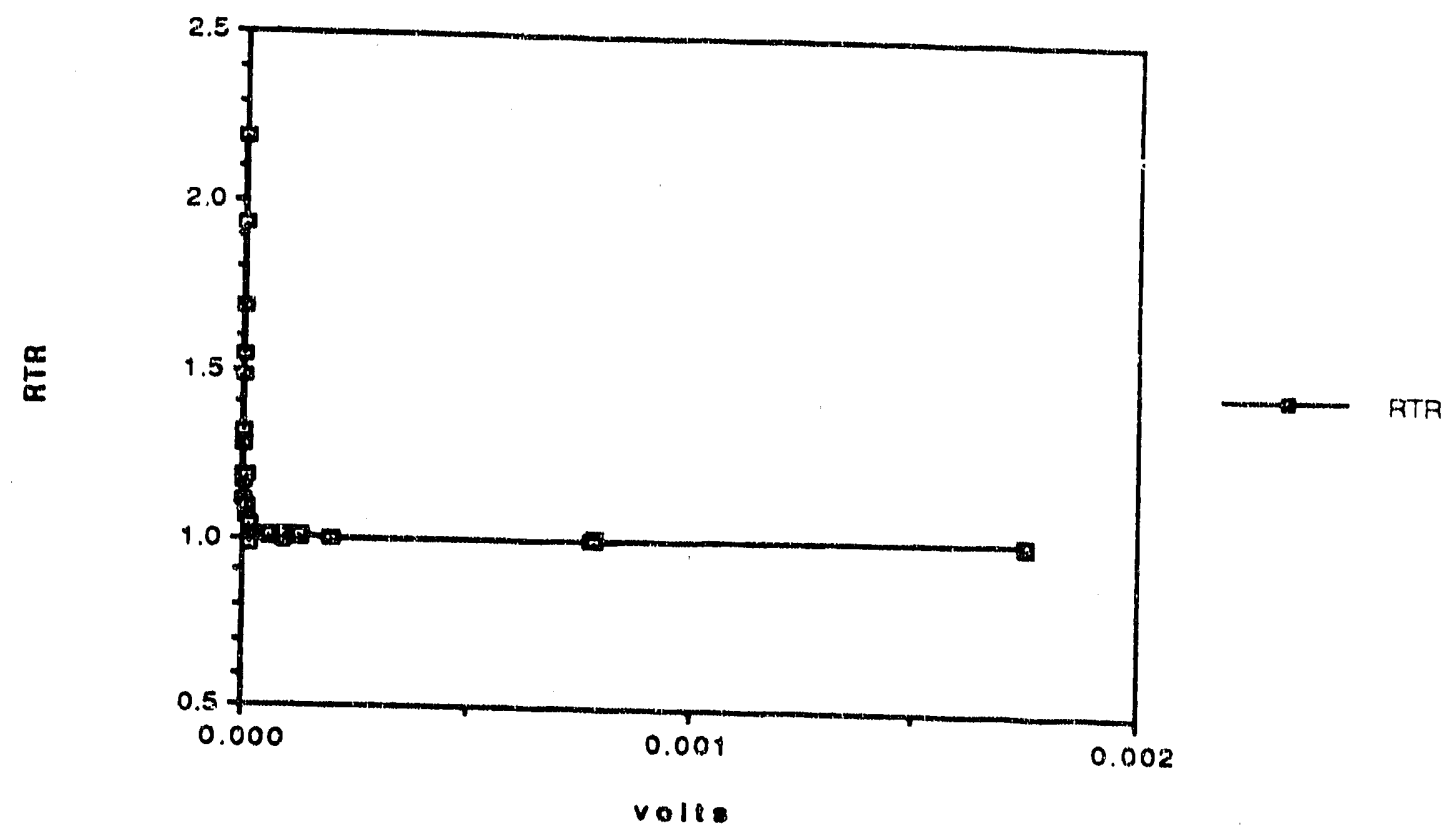

Figure 2.2

Joule Heating Test

APM Rod Serial \#003

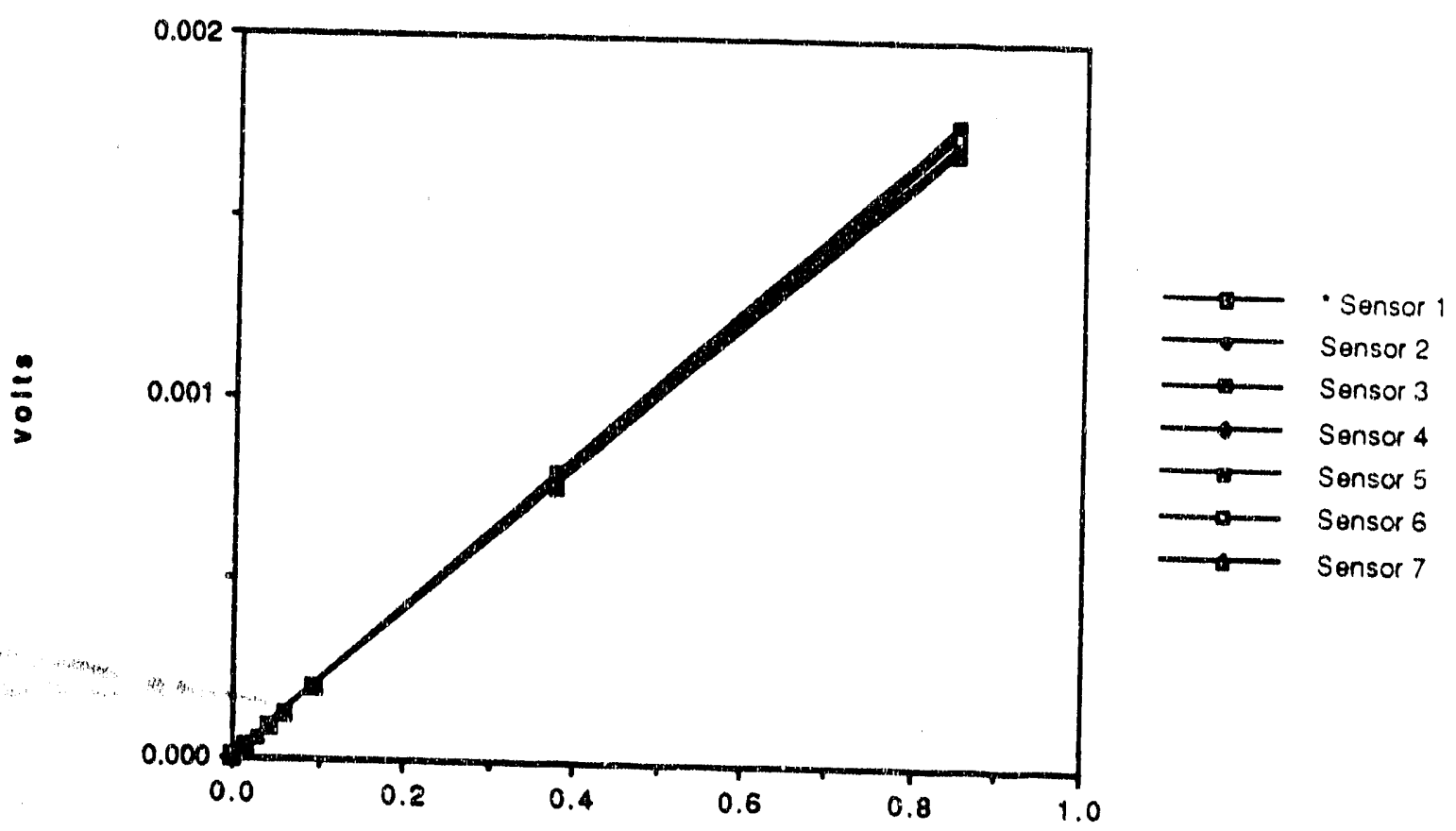

Wottelgram 
Figure 2-3

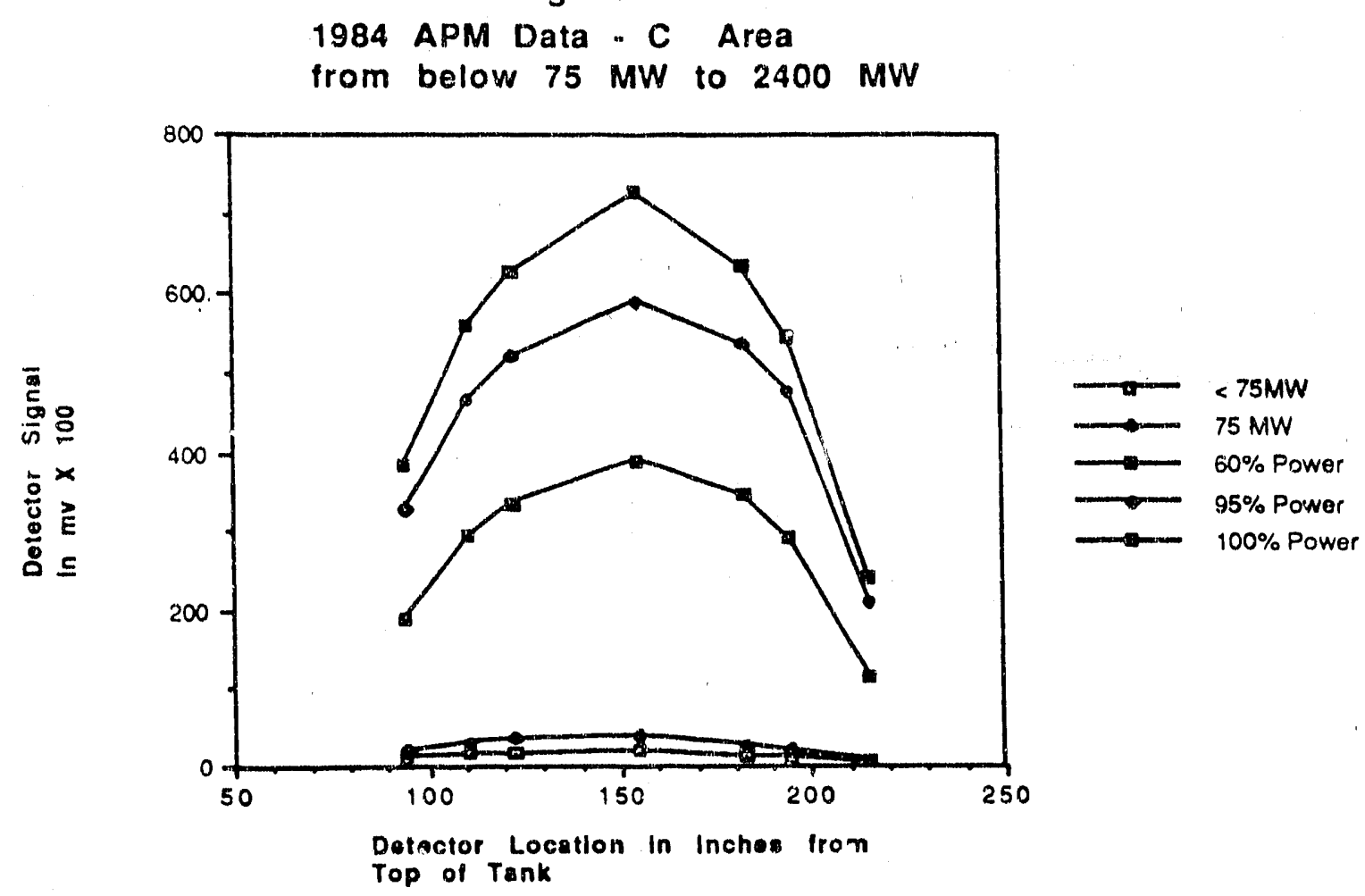

Figure 2.4

1984 APM Data - C Area

from below $75 \mathrm{MW}$ to $75 \mathrm{MW}$

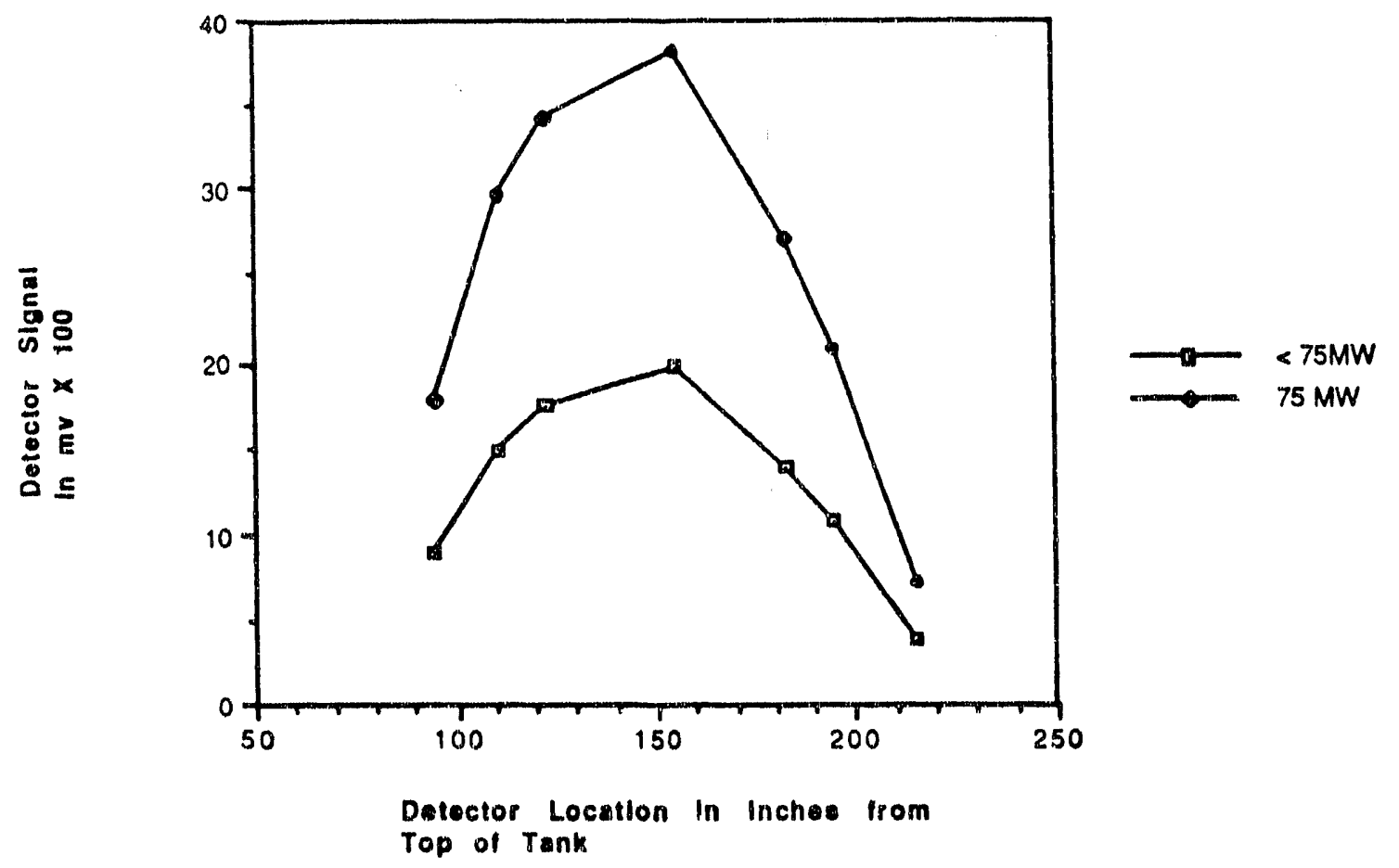


WSRC-RP-92-594

Figure 2-5

Data from $K$ Area

APM Rod $\$ 5$

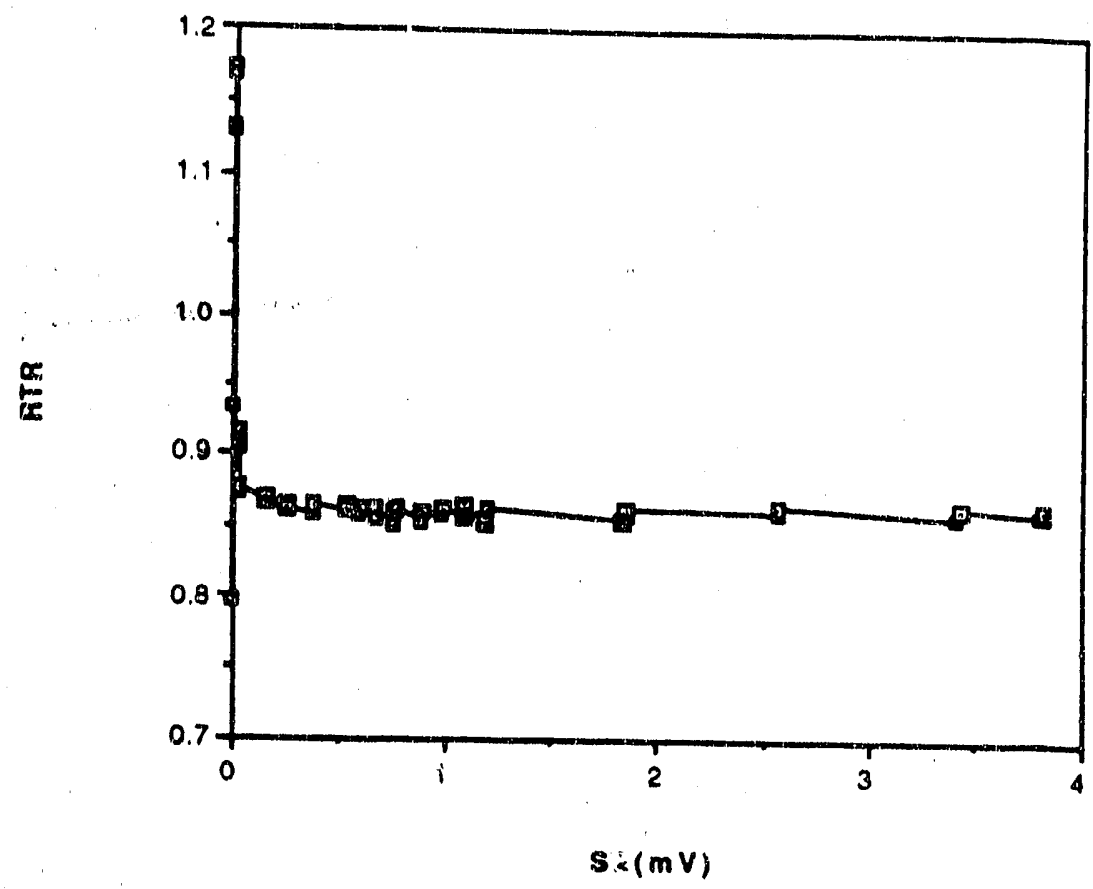

- ATR

Figure 2-6

Data from $K$ Area

AFA Rod \#5

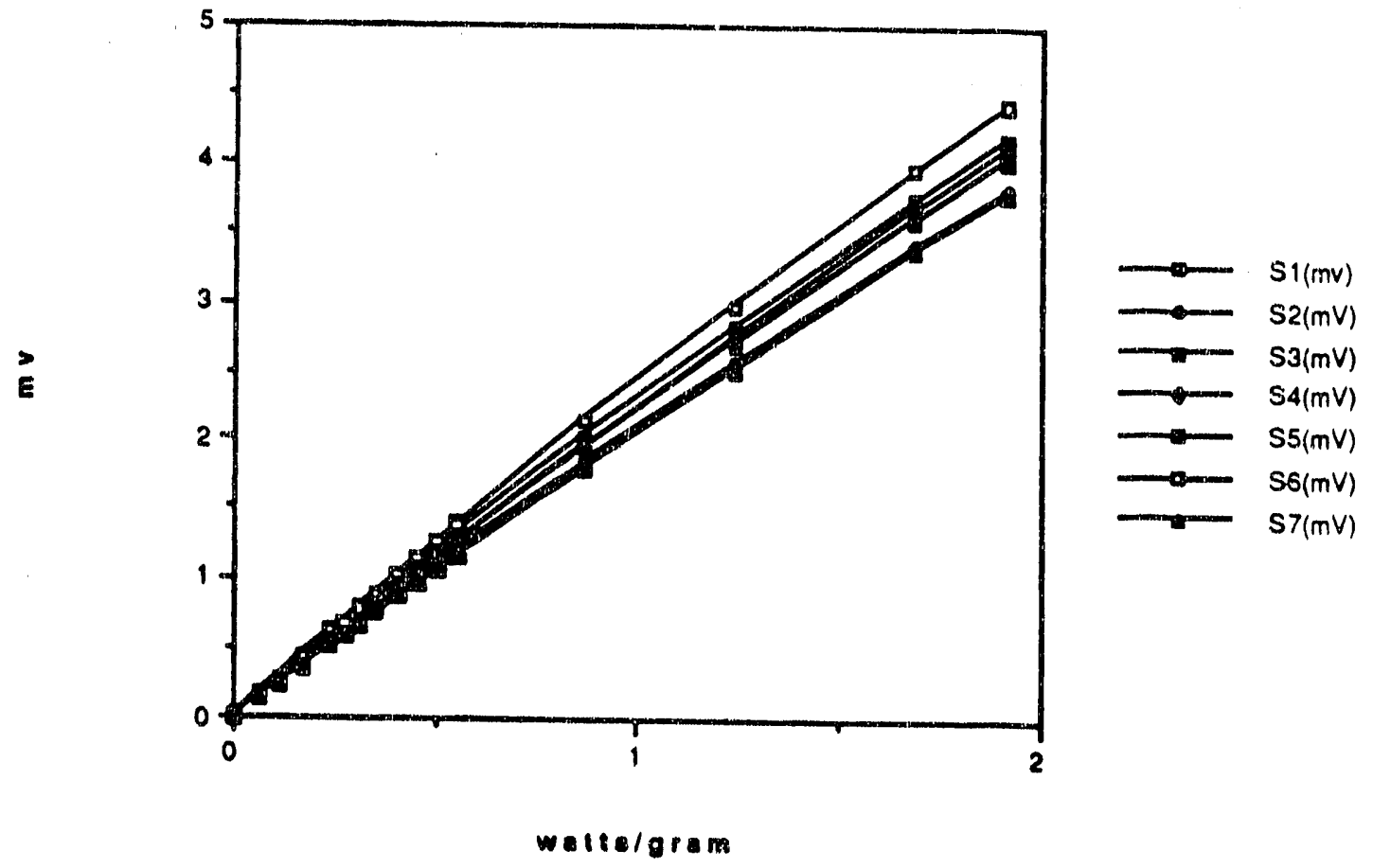


Figure 2.7 APM Rod 39 . Cable Data

Sensor 2
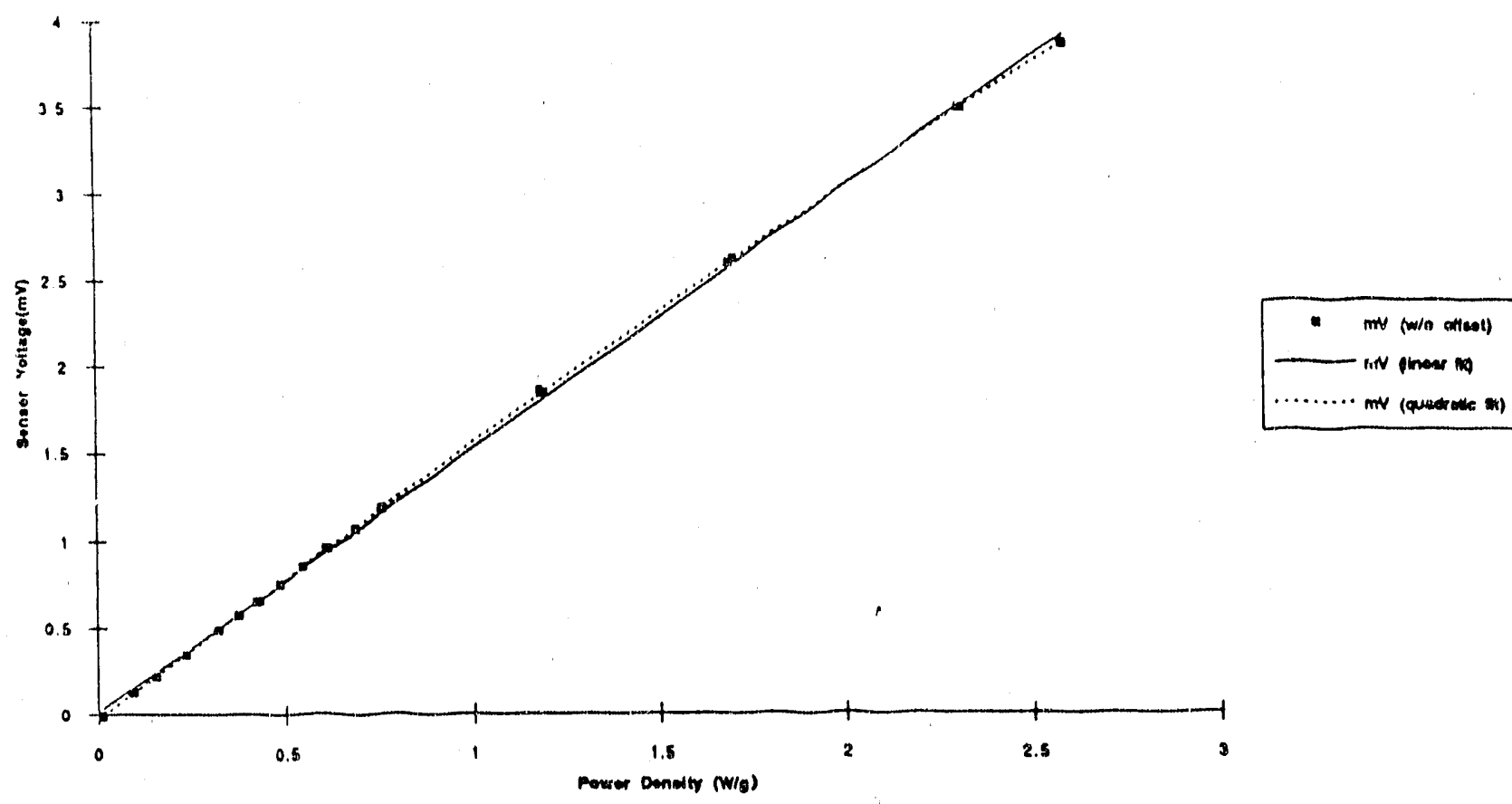

Figure2-8 RTR (raw data)

Delta-M, Rod 39, Cabje Heating

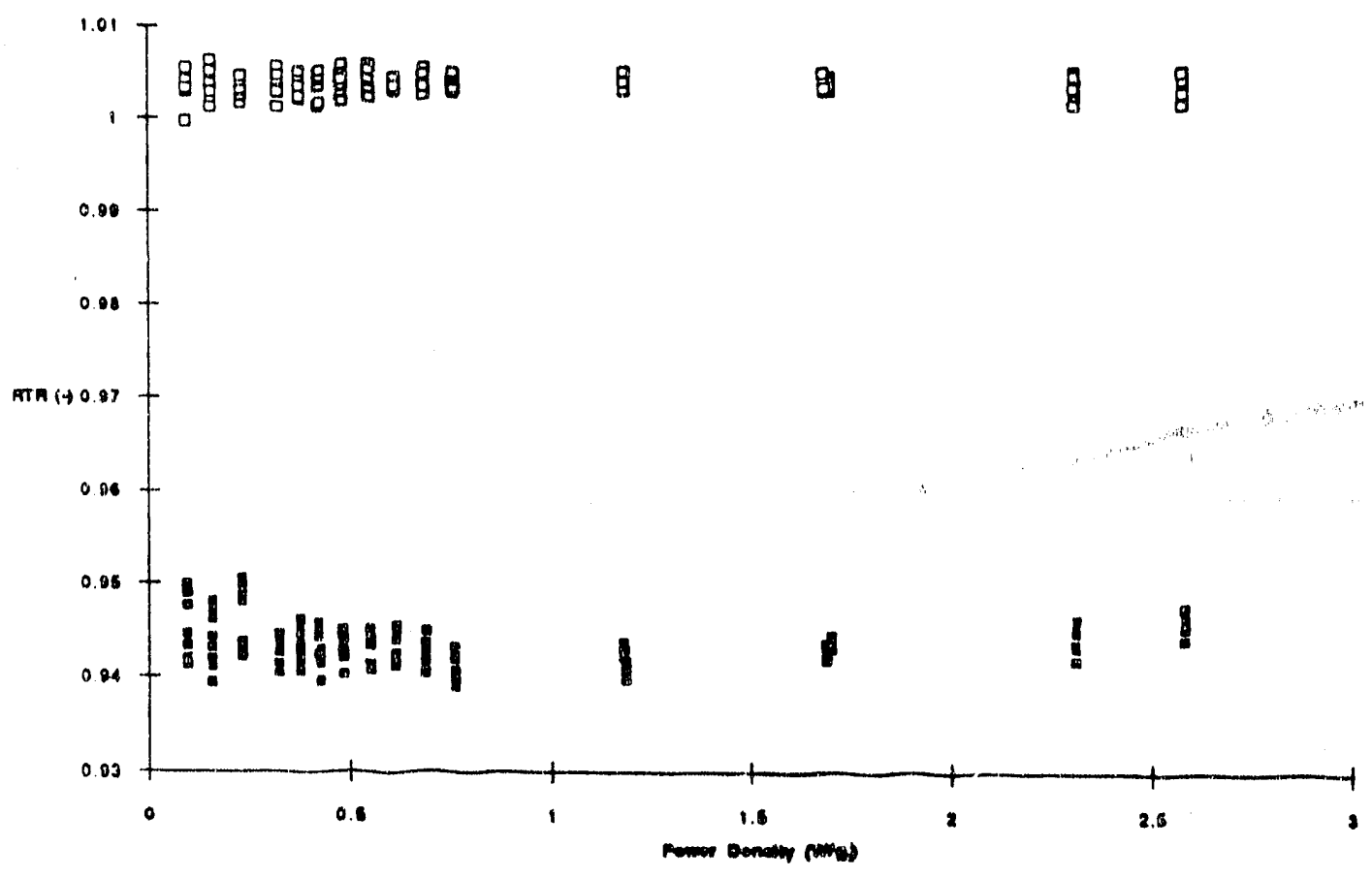

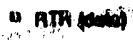

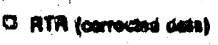


WSRC-RP-92-594

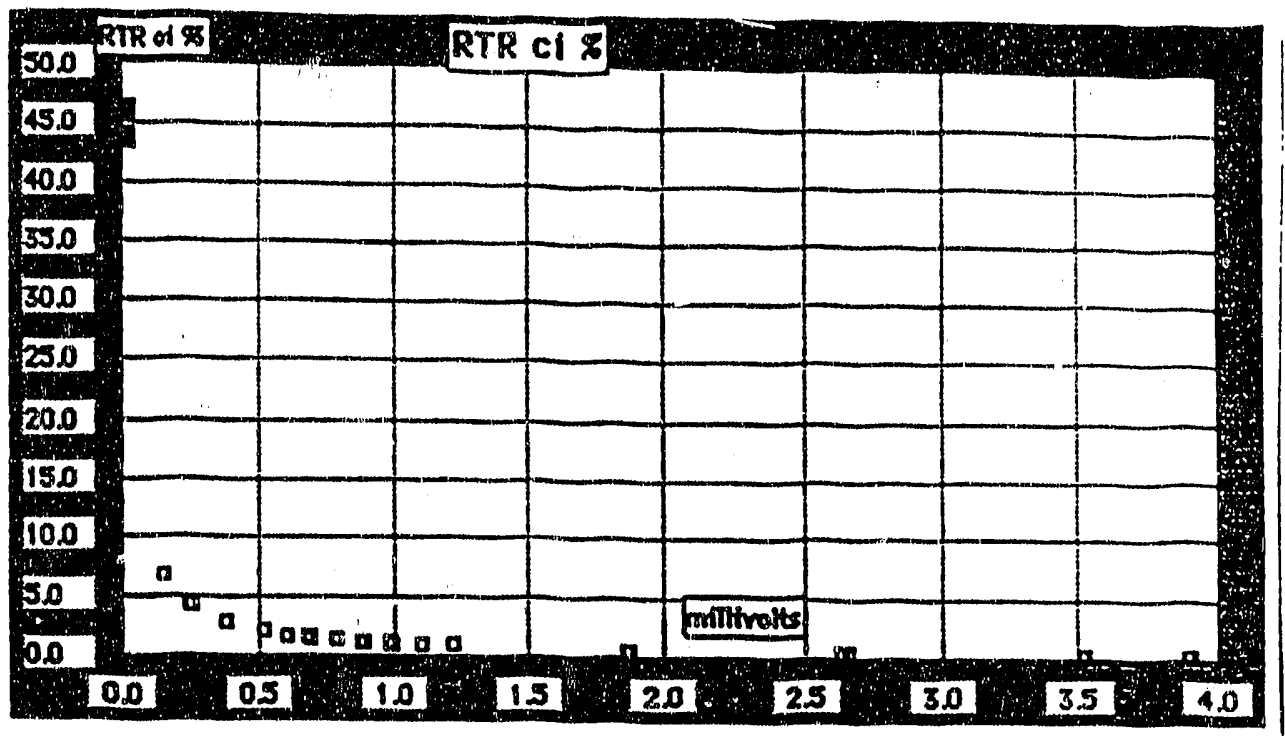

Fig. 2-9 RTR Confidence Interval

Rod 39, Cable Heating, Forward Flow, 0.2 fps

Figure 2-10 APM Rad 39. Joule Date

Sonsor 2

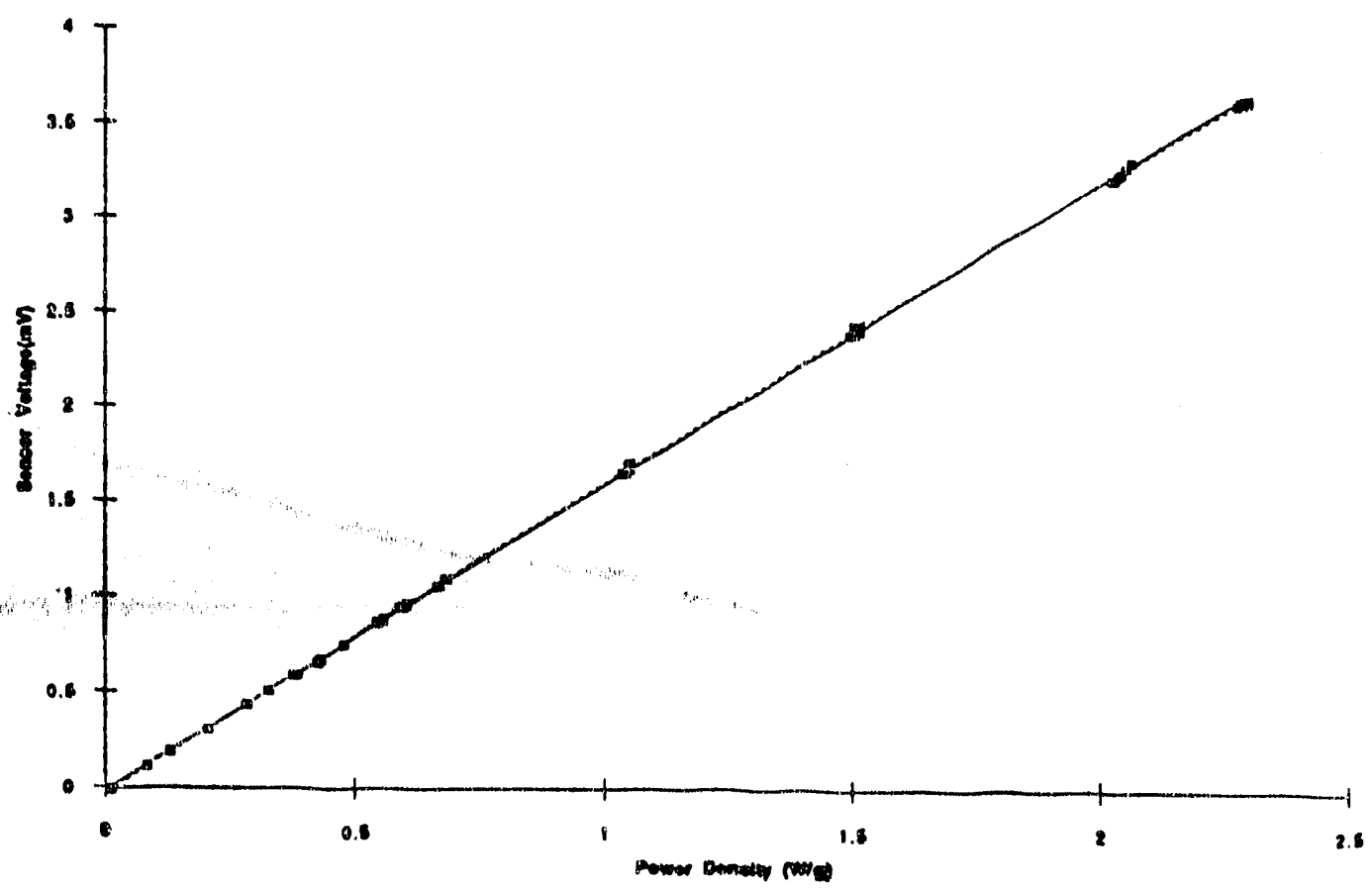


WSRC-RP-92-594

Fig. 2.11 WTA foum delas

Jouls thelong, Rod as

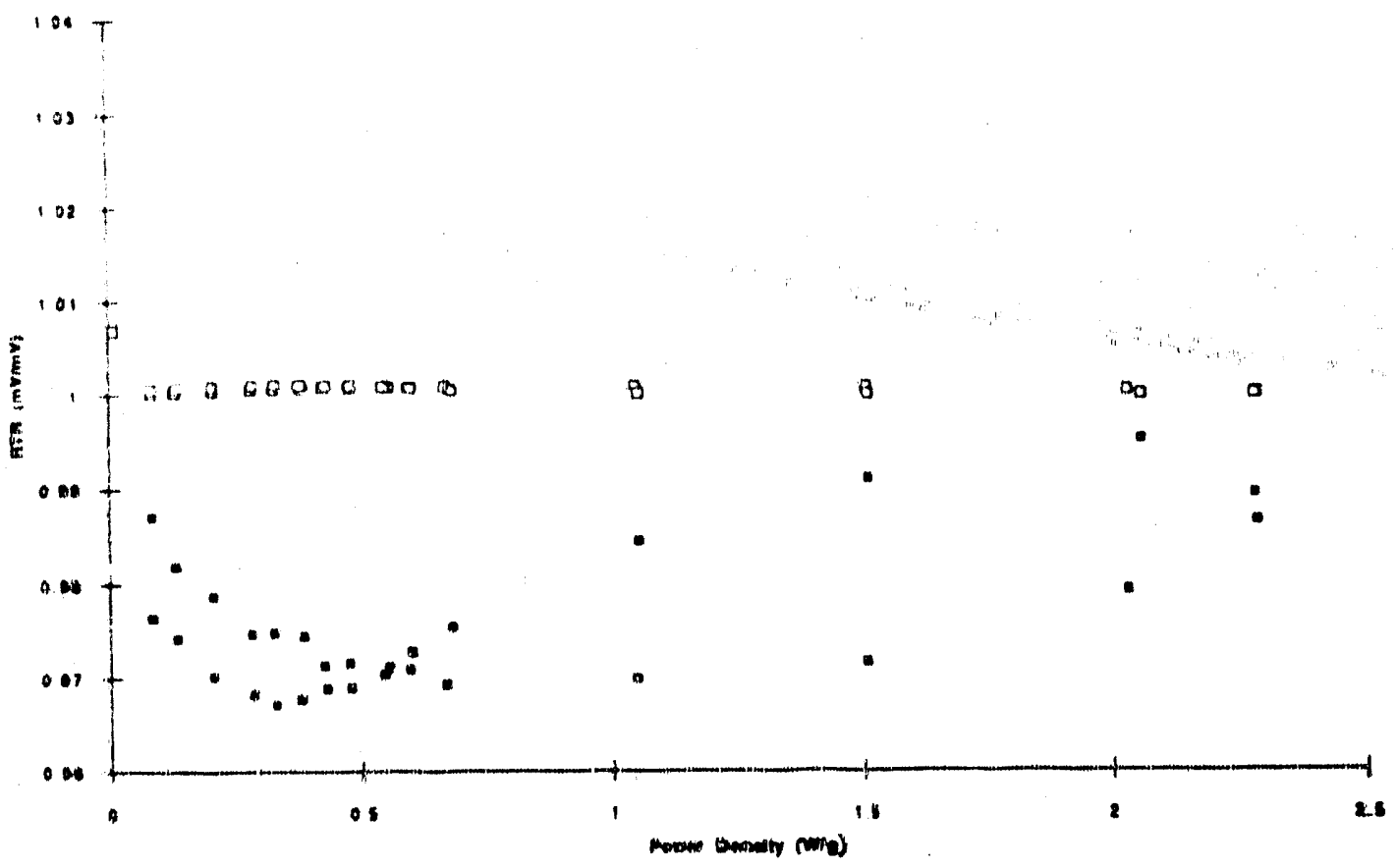

- min vomian

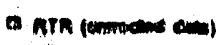

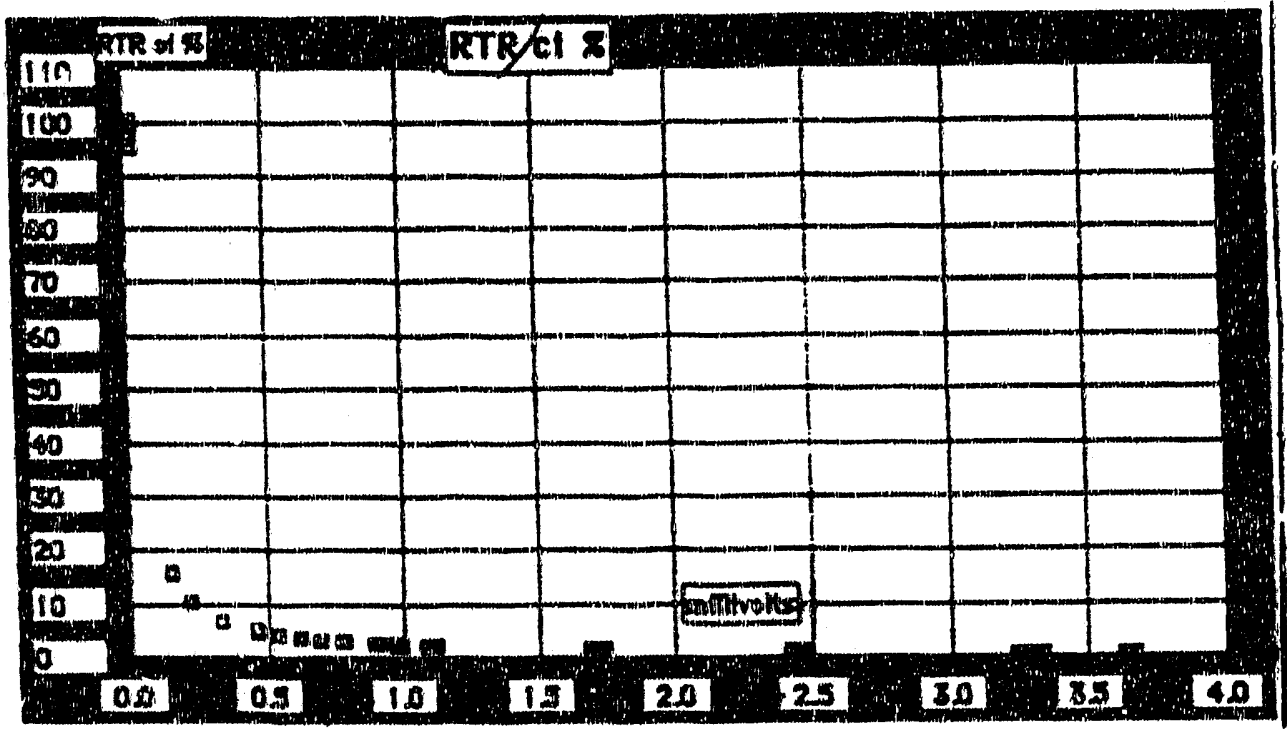

Fig. 2-12 RTR Confidence Interval

Rod 39, Joule Hemting, Forwand Flow, 0.2 fpe 
FW. 2.19 RTh (rew dall, ceble hardro ond

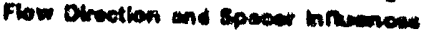

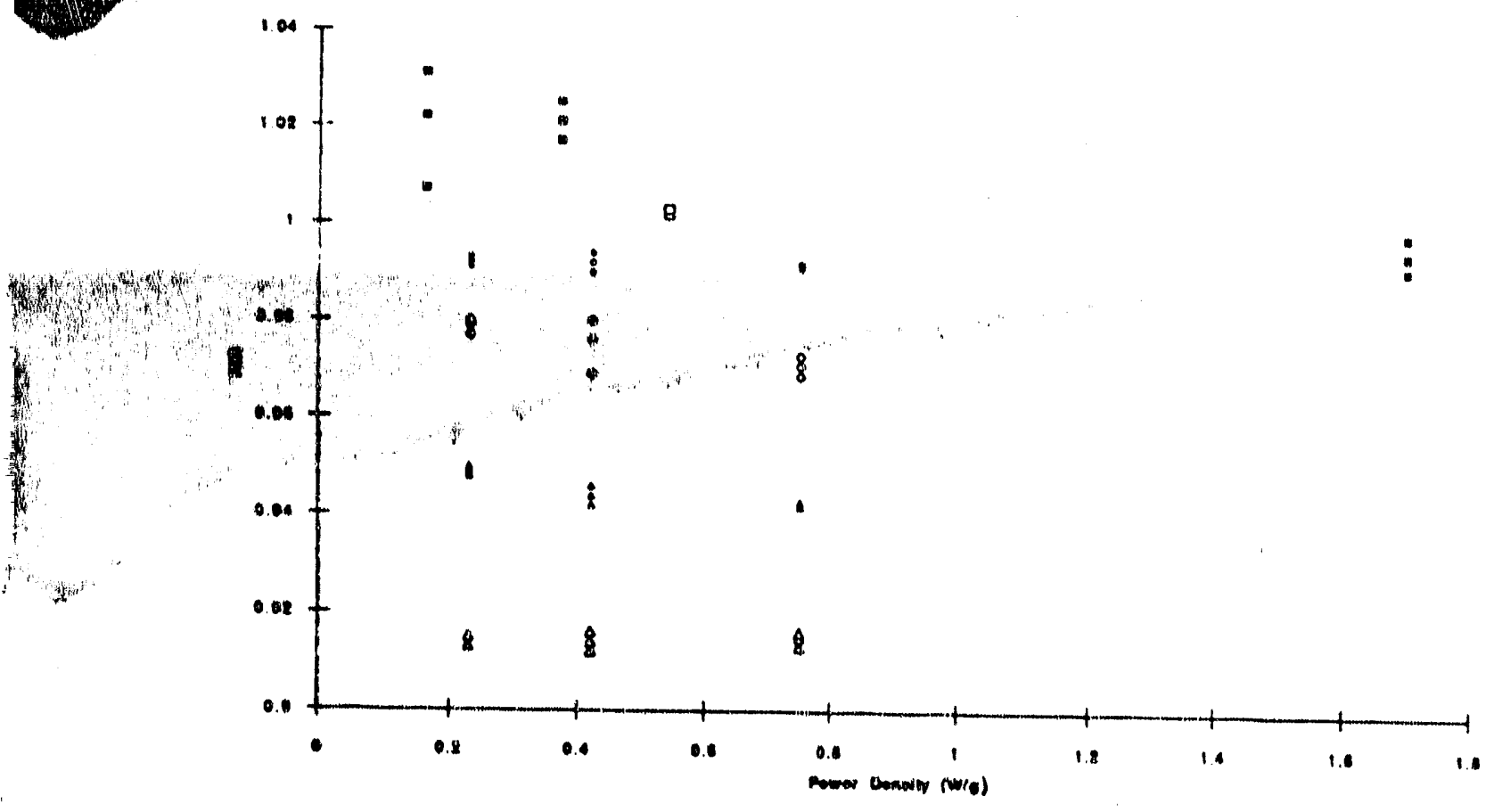

Mpure 2.16 RTI (raw dato)

Epaces, 0.2 pe Forward Flow, Cablo Henter

$116-$

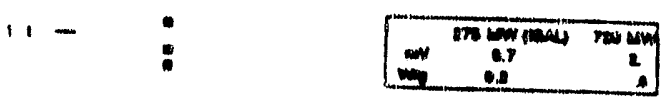
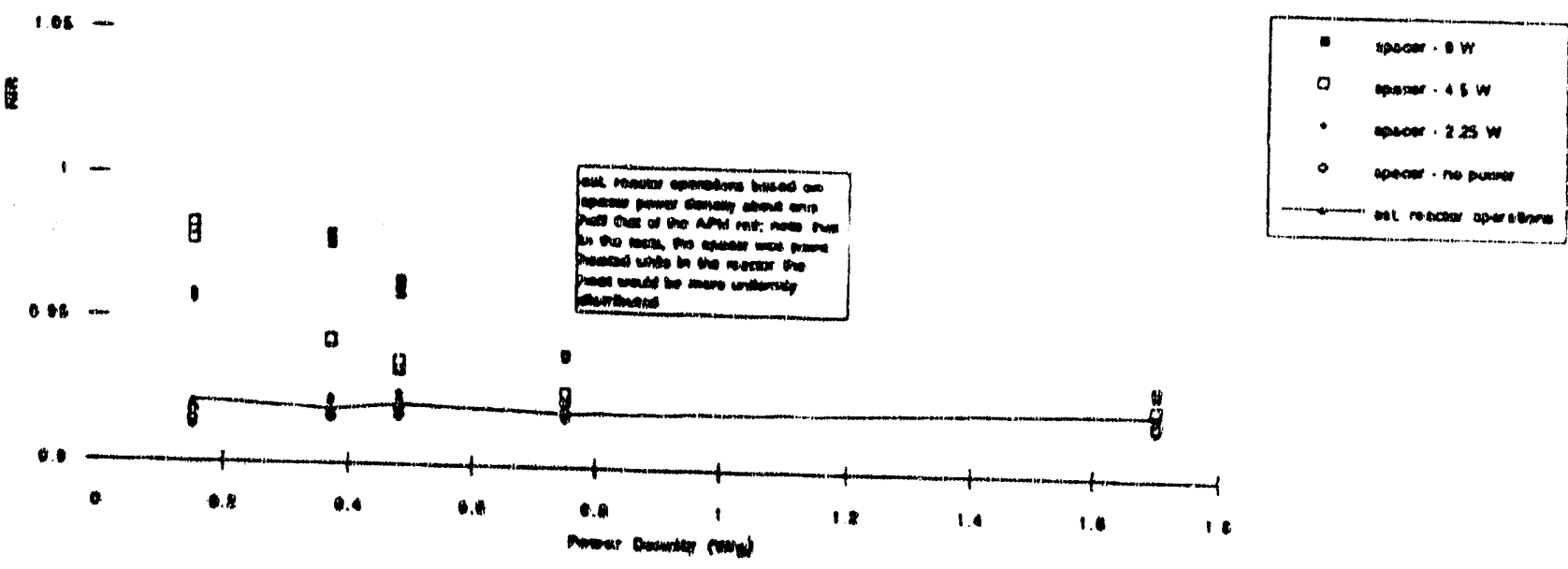
WSRC-RP-92-594

Figure 2-13 Erfoct of Floated Spacer

with no now and Cable Heacles:
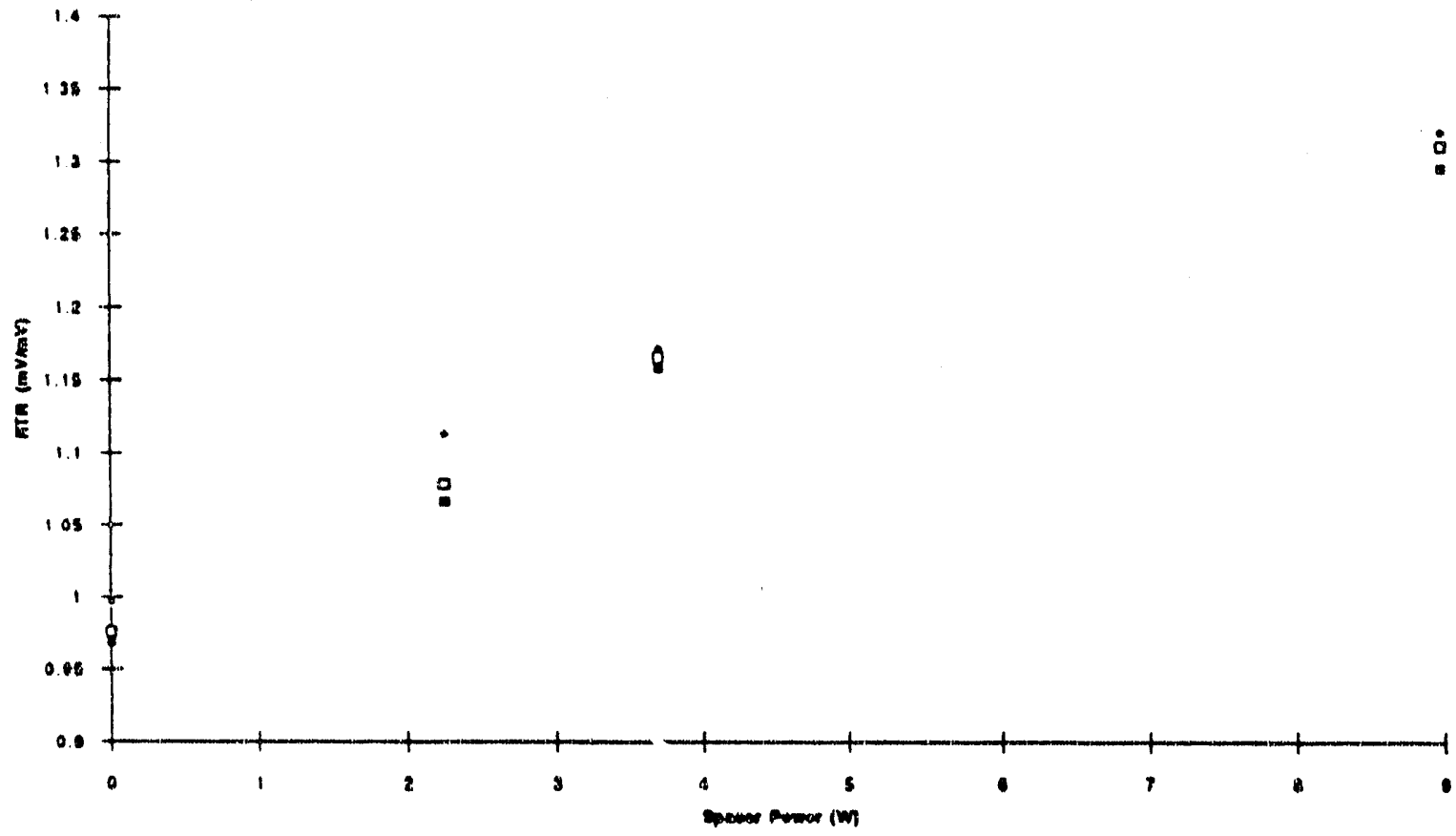

-

O mone

- not 
WSRC-RP-92-594

\subsection{CHANNEL STATISTICAL ANALYSIS}

\section{Backaround}

The channel statistical analysis (CSA) followed the methodology used in the commercial nuclear industry to investigate the potential sources of channel uncertainties. The CSA considered the path from the APM sensor output to the Control Computer. The millivolt (mV) signals generated by the APM sensors are applied to the Control Computer through the junction boxes, a crossbar switch, a noise filter, and an analog to digital converter (ADC). The Control Computer uses this input in the software algorithms, to calculate the roof-topratio (RTR), consisting of the Sensor 2 and Sensor 6 inputs. The RTR provides information on the axial power profile within the reactor.

\section{Evaluation Analysio and Results}

Data taken from the K-Reactor APM rods and the methodology applied for statistical analysis were evaluated and considered to be an adequate representation of the sensor uncertainties. The channel signal path uncertainty is composed of the uncertainty associated with the ADC. The junction boxes, crossbar switches, and noise filter do not contribute any uncertainties to the processed signal. Each time a sensor is read by the Control Computer, the $A D C$ channel uncertainty is applied to the sensor uncertainty to give the total uncertainty of the sensor input as processed by the Control Computer. The worst case contribution for the channel uncertainty of the $A D C$ is $10 \mu \mathrm{V}$ deviation per vendor specifications, with a one-sided boundary on the error, for the $10 \mathrm{mV}$ scale. The full scale input range is $\pm 10 \mathrm{mV}$. For example, a $4 \mathrm{mV}$ sensor response after the ADC could result in a reading of $4.01 \mathrm{mV}$ or $3.99 \mathrm{mV}$. The sensor and channel uncertainties were accounted for within the same statistical model as described in the "Statistical Analysis" Section 4.0. The following assumptions were made for the ADC uncertainties associated with each sensor output for use in the statistical model: it is random error; errors among sensors are independent because they are read at different times; the expected error is zero when the ADC is properly calibrated; the error is normally distributed; and the error is additive to the sensor $m V$ value. This result was incorporated into the RTR statistical analysis described in Section 4.0.

\subsection{STATISTICAL ANALYSIS}

\section{Backarnund}

The goal of the Axial Power Monitor (APM) statistical analysis was to demonatrate with $95 \%$ confidence that the extremes of the range of RTR endysis are sufficient when uncertainties are considered to ensure that Technical Specification limits on RTR are adequate.

Data available for this statistical analysis has been described in Section 2, Test Data. Specifically the Axial Power Monitor - Data Acquisition System (APMDAS) data for the nine APM rods installed in K-Reactor were analyzed. 
Although a detailed analysis of the Delta-M data was not undertaken, a review of their data indicated that they are consistent with the SRS observations.

An anomaly was identified in the data for APM rod \#6 which will be adodressed in the discussion of results. To gain insight into this anomaly, the data taken with the K-Reactor Control Computer were analyzed.

\section{Statistical Method}

A statistical methodology was developed whicti defined the ATR as a function of the watts per gram applied to one of the sensors (Sensor 6) used to calculate RTR and the power ratio (Sensor 2 divided by Sensor 6 ). The statistical methodology was designed to account for the calibration data for the individual sensors provided by Delta-M at the time of rod shipment, the uncertainty (including bias) in the experimental data taken at SRS, and the channel uncertainty analysis, which was discussed in Section 3 "Channel Statistical Analysis." From these data and the application of propagation of error techniques to the RTR function, the predicted function value and its variance can be computed. This statistical methodology was implemented by using the SAS ${ }^{\text {TM }}$ System Software developed by the SAS Institute Inc.

A team, independent of the development and analysis team, reviewed the statistical method to ensure its validity for this application. The review team performed a line-by-line review of the $S A S^{\text {Th }}$ software code to ensure its correct implementation. Ad hoc checks verified the results from the SAS ${ }^{\mathrm{m}}$ system.

\section{Analysis and Resulis}

Section 5.0 "Safoty Analysis" describes the importance of assuring that the RTR is within specific limits. Thus the key result of the statistical analysis is a determination at a $95 \%$ confidence level of the extremes of the RTR range that can result from reactor operation.

As described in Section 2.0 "Test Data" the experimental data base has recently been considerably augmented. Reactor data was taken for rods \#1 through \#4 in the range of APM rod heating rates from 0.01 to 0.3 watts per gram which corresponds approximately to the range 20 to $600 \mathrm{MW}$. reactor power. depending on rod location and the axial power shape. For rods \#5 through \#9 data was taken up to 2 watts per gram, which is the APM rod design range, with emphasis on the region from 0.01 to 0.3 watts per gram. The expected detector response for $270 \mathrm{MW}$ is shown in Table 4-1.

The results of the analysis of calibration data, taken on the installed rods with 6 DC pump flow, show that Sensor 2 and Sensor 6 have different sensitivities in the installed configuration. This means that the ratio of Ser,1sor 2 to Sensor 6 is not unity for uniform intermal heating input. Figure $4-1$ shews the calibration data for Sensors 2 and 6 for APM rod $\$ 3$ and Figure 4-2 shows the calibration data for APM rod \#8. This bias is steady and repeatable over the range of data laken in the realctor and is a different value for each rod. 
The statistical analysis results are shown in Tables 4-2, 4-3, and 4.4 for heating rates of $0.15,0.2$, and 0.3 watts per gram, respectively. These heating rates tables show the one sigma uncertainty in a single reading, and $0.8 \mathrm{mV}$. The mean. This quantity is the combination of the spreading of RTR around the curve and the signal processing or channel uncertainty provided to indicate the repeatability of the Ancertainty from Section 3.0. It is provides the average value of the bias over the readings. The table also gram.

It is noted that rod \#6 shows an anomalous uncertainty value and bias when all the data up to 2 watts per gram are considered. The data for rod \#6 are shown in Figure 4-3. The results illustrated in Figure 4-3 for rod \#6 have been confirmed by an alternate method (Control Computer data logging) and have been demonstrated to be repeatable. The data for all other rods in this group follow the pattern of rod \#8 (Figure 4-2) indicating that some sensors in rod \#6 are anomalous in certain ranges. Sensors 2 and 6 are well behaved in the range of interest (below 1 watt/gram) and may be considered functional for determining RTR. However, it is apparent that rod 6 must be considered suspect. Seven out of the nine rods are required for reactor operation per Technical Specifications, so if necessary rod six may be declared inoperable, and reactor operation can continue within the analyzed safety basis.

The tables show the extremes of RTR that would result from reactor operation if no correction is made for the bias and also if a separate bias is applied to the ATR from each rod. These extremes are calculated at the $95 \%$ confidence level and assume for the low value that the observed RTR is 0.8 and for the high value that the observed ATA is 1.2 . 
Table 4-1

TYPICAL APM DETECTOR RESPONSE

Nominal Detector Response at $270 \mathrm{MW}$ (ISAL) and RTR $=1.0$

\begin{tabular}{|c|c|c|c|}
\hline APM POSITION \# & APM SERIAL\# & WATTS/GRAM & OUTPUT (ImV) \\
\hline 6 & 21 & 0.16 & 0.43 \\
9 & 30 & 0.25 & 0.67 \\
5 & 19 & 0.25 & 0.67 \\
7 & 16 & 0.30 & 0.78 \\
8 & 24 & 0.30 & 0.79 \\
4 & 33 & 0.32 & 0.83 \\
3 & 32 & 0.33 & 0.86 \\
2 & 15 & 0.35 & 0.91 \\
1 & 20 & 0.36 & 0.95 \\
\hline
\end{tabular}

Table 4-2

SUMMARY OF APM ROD ROOF-TOP-RATIO UNCERTAINTIES

HEATING RATE $=0.15$ watts/gram $(\approx 0.4 \mathrm{mV})$

\begin{tabular}{|c|c|c|c|c|}
\hline $\begin{array}{l}\text { Reactor } \\
\text { Position }\end{array}$ & $\begin{array}{l}\text { RTR Uncerainties } \\
\text { at } 1 \sigma \text { about the } \\
\text { Catibration Mean } \\
\text { (Note 1) }\end{array}$ & $\begin{array}{c}\text { Bias } \\
\text { (Note 2) }\end{array}$ & $\begin{array}{l}\text { Uncorrected RTR } \\
\text { (Min-Max) } \\
\text { 95\% Confidence } \\
\text { (Note 3) }\end{array}$ & $\begin{array}{c}\text { Blased RTR } \\
\text { (Min-Max) } \\
\text { 95\% Confidence } \\
\text { (Note 3) }\end{array}$ \\
\hline Rod \#1 & $2.67 \%$ & 0.843 & $0.900-1.508$ & $0.753-1.254$ \\
\hline Rod \#2 & $1.93 \%$ & 0.962 & $0.809-1.290$ & $0.770 \cdot 1.240$ \\
\hline Rod \#3 & $2.82 \%$ & 0.900 & $0.839-1.400$ & $0.750-1.255$ \\
\hline Rod \#4 & $2.09 \%$ & 0.850 & $0.894 \cdot 1.471$ & $0.764-1.247$ \\
\hline Rod 6 (Note 4) & $2.48 \%$ & 1.002 & $0.754 \cdot 1.260$ & $0.754-1.258$ \\
\hline Rod $\# 5$ & $3.11 \%$ & 0.859 & $0.874 \cdot 1.470$ & $0.748-1.264$ \\
\hline Rod \#6 & $13.15 \%$ & 1.044 & $0.553 \cdot 1.373$ & $0.577-1.433$ \\
\hline Rod \#7 & $3.28 \%$ & 0.865 & $0.868-1.368$ & $0.745 \cdot 1.265$ \\
\hline Rod $\# 8$ & $3.74 \%$ & 0.815 & $0.915-1.501$ & $0.737 \cdot 1.274$ \\
\hline Rod $\# 9$ & $3.64 \%$ & 0.883 & $0.872 \cdot 1.440$ & $0.739 \cdot 1.272$ \\
\hline
\end{tabular}

Note 1. The first set of entries in this colurin are based on data from 0.01 to 0.4 watts/gram, the second is based on 0.01 to 1.9 watts/gram.

Note 2. In all cases this is the average bias from 0.1 to 0.3 watts/gram.

Note 3. For an observed operating band of 0.8 to 1.20.

Note 4. This entry for Rod $\# 6$ uses data only from the range 0.01 to 0.4 watts/gram. 


\section{Table 4-3}

SUMMARY OF APM ROD ROOF-TOP-RATIO UNCERTAINTIES HEATING RATE $=0.20$ watts $/ \mathrm{gram}(\cong 0.53 \mathrm{mV})$

\begin{tabular}{|l|c|c|c|c|}
\hline $\begin{array}{c}\text { Reactor } \\
\text { Position }\end{array}$ & $\begin{array}{c}\text { RTR Uncentainties } \\
\text { at lo about the } \\
\text { Calibration Mean } \\
\text { (Note 1) }\end{array}$ & $\begin{array}{c}\text { Bias } \\
\text { (Note 2) }\end{array}$ & $\begin{array}{c}\text { Uncorrected RTR } \\
\text { (Min-Max) } \\
95 \% \text { Confidence } \\
\text { (Note 3) }\end{array}$ & $\begin{array}{c}\text { Biased RTR } \\
\text { (Min-Max) } \\
\text { 95\% Confidence } \\
\text { (Note 3) }\end{array}$ \\
\hline Rod \#1 & $2.01 \%$ & 0.843 & $0.912-1.495$ & $0.764-1.241$ \\
Rod \#2 & $1.46 \%$ & 0.962 & $0.807-1.281$ & $0.775-1.230$ \\
Rod \#3 & $2.12 \%$ & 0.900 & $0.844-1.376$ & $0.762-1.241$ \\
Rod \#4 & $1.58 \%$ & 0.850 & $0.896-1.460$ & $0.772-1.232$ \\
Rod \#6 (Note 4) & $1.86 \%$ & 1.002 & $0.761-1.241$ & $0.763-1.243$ \\
\hline Rod \#5 & $2.34 \%$ & 0.859 & $0.890-1.454$ & $0.760-1.249$ \\
Rod \#6 & $9.90 \%$ & 1.044 & $0.603-1.322$ & $0.630-1.380$ \\
Rod \#7 & $2.47 \%$ & 0.865 & $0.880-1.352$ & $0.758-1.250$ \\
Rod \#8 & $2.82 \%$ & 0.815 & $0.930-1.543$ & $0.752-1.256$ \\
Rod \#9 & $2.74 \%$ & 0.883 & $0.857-1.447$ & $0.753-1.256$ \\
\hline
\end{tabular}

Note 1. The first set of entries in this column are based on data from 0.01 to 0.4 watts/gram, the second is based on 0.01 to $1.9 \mathrm{watts} / \mathrm{gram}$.

Note 2. In all cases this is the average bias from 0.1 to 0.3 watts/gram.

Note 3. For an observisd operating band of 0.8 to 1.20.

Note 4. This entry for Rod $\# 6$ uses data only from the range 0.01 to 0.4 watts/gram. 
WSRC-RP-92-594

Table 4-4

SUMMARY OF APM ROD ROOF-TOP-RATIO UNCERTAINTIES

HEATING RATE $=0.30$ watts $/ \mathrm{gram}(\cong 0.8 \mathrm{mV})$

\begin{tabular}{|l|c|c|c|c|}
\hline $\begin{array}{c}\text { Reactor } \\
\text { Position }\end{array}$ & $\begin{array}{c}\text { RTR Uncertainties } \\
\text { at 10 about the } \\
\text { Calibration Mean } \\
\text { (Note 1) }\end{array}$ & $\begin{array}{c}\text { Bias } \\
\text { (Note 2) }\end{array}$ & $\begin{array}{c}\text { Uncorrected RTR } \\
\text { (Min-Max) } \\
95 \% \text { Confidence } \\
\text { (Note 3) }\end{array}$ & $\begin{array}{c}\text { Biased RTR } \\
\text { (Min-Max) } \\
95 \% \text { Contidence } \\
\text { (Note 3) }\end{array}$ \\
\hline Rod \#1 & $1.36 \%$ & 0.843 & $0.924-1.488$ & $0.776-1.231$ \\
Rod \#2 & $0.98 \%$ & 0.962 & $0.807-1.273$ & $0.783-1.222$ \\
Rod \#3 & $1.42 \%$ & 0.900 & $0.856-1.372$ & $0.775-1.232$ \\
Rod \#4 & $1.06 \%$ & 0.850 & $0.920-1.465$ & $0.781-1.224$ \\
Rod \#6 (Note 4) & $1.25 \%$ & 1.002 & $0.775-1.227$ & $0.777-1.229$ \\
\hline Rod \#5 & $1.57 \%$ & 0.859 & $0.903-1.437$ & $0.773-1.234$ \\
Rod \#6 & $6.66 \%$ & 1.044 & $0.653-1.270$ & $0.682-1.326$ \\
Rod \#7 & $1.65 \%$ & 0.865 & $0.894-1.437$ & $0.771-1.234$ \\
Rod \#8 & $1.89 \%$ & 0.815 & $0.944-1.525$ & $0.767-1.239$ \\
Rod \#9 & $1.84 \%$ & 0.883 & $0.871-1.407$ & $0.768-1.239$ \\
\hline
\end{tabular}

Note 1. The first set of entries in this column are based on data from 0.01 to 0.4 watts/gram, the second is based on 0.01 to 1.9 watts/gram.

Note 2. In all cases this is the average bias from 0.1 to 0.3 watts/gram.

Note 3. For an observed operating band of 0.8 to 1.20 .

Note 4. This entry for Rod $\$ 6$ uses data only from the range 0.01 to 0.4 waits/gram. 
Figure 4-1

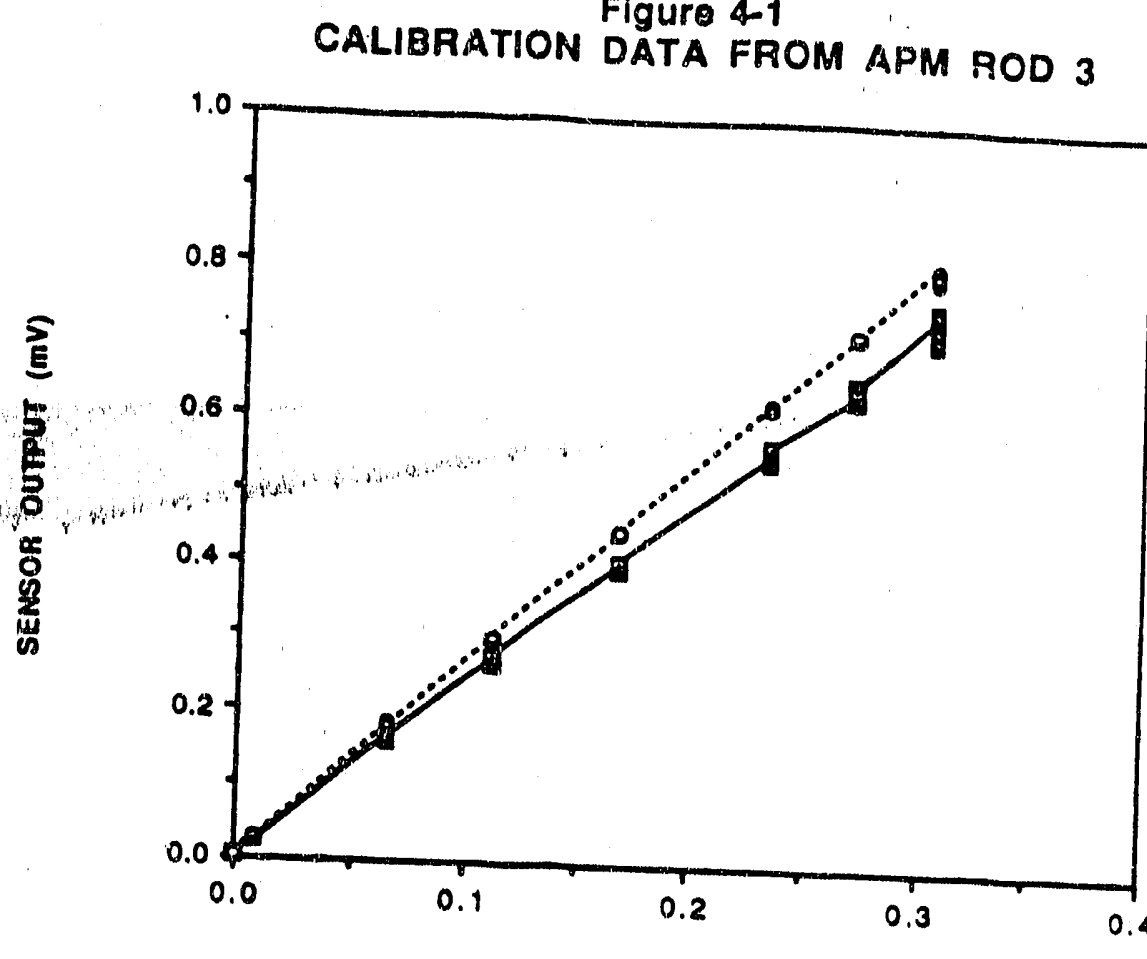

Wom Sensor 2

INTEANAL NEATINO RATE (wane/gram)

Figure 4-2

CALIBRATION DATA FPOM APM ROD 8

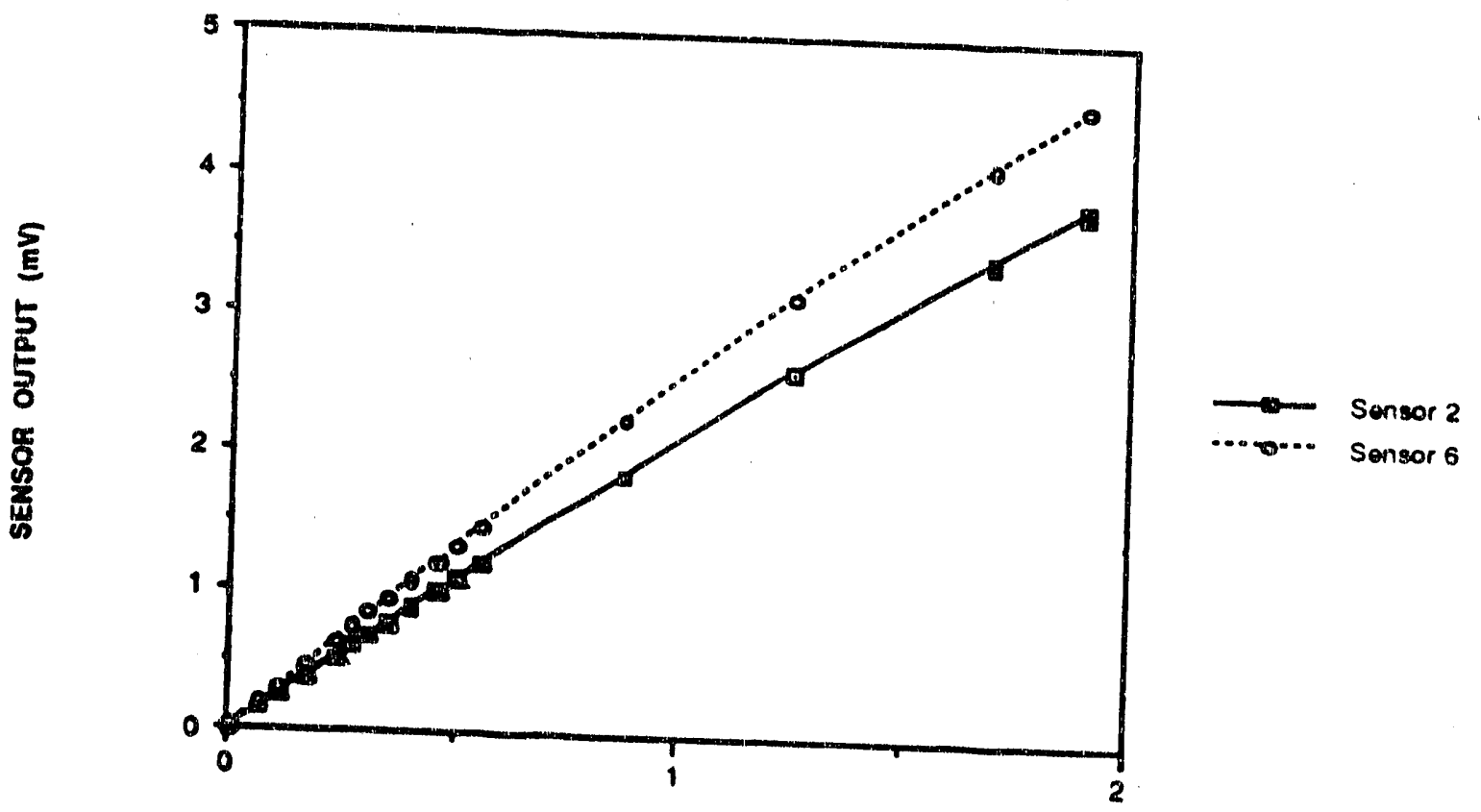

IATERANAL HEATINO RATE (warte/gram) 
FIGURE 4-3

CALIBRATION DATA FROM APM ROD 6

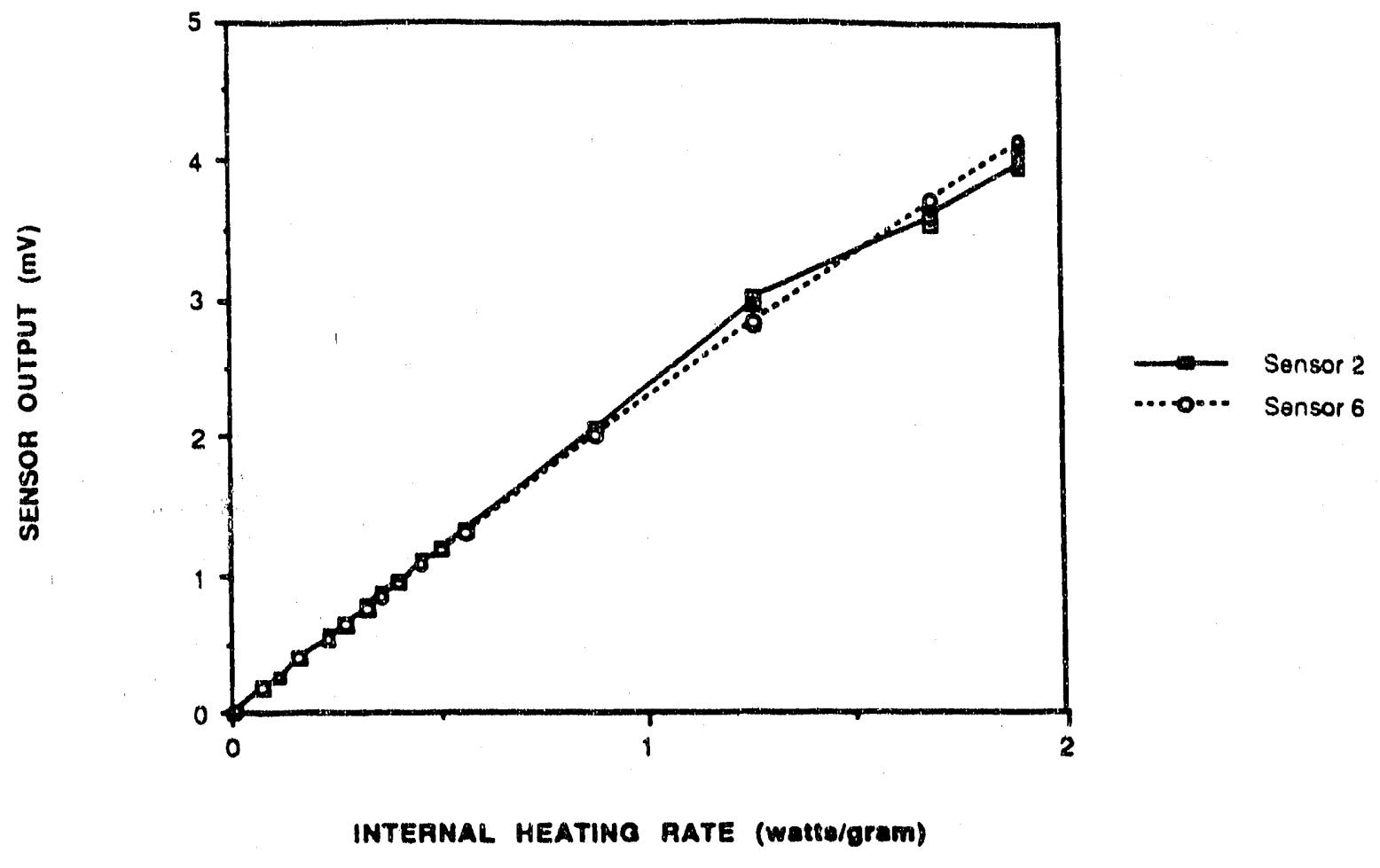




\section{B.0 SAFETY ANALYSIS}

Safety analyses have been performed to confirm that the conclusions of the Safety Analysis Report (SAR) are not affected by the APM rod uncertainty allowances described previously in Section 4.0. Therefore, the APMs are adequate to support safe operation of K-Reactor up to $720 \mathrm{MW}$ (30\% of historical power).

The safety analyses employ coupled neutronic and thermal-hydraulic computer simulations of the various desigin basis events (DBEs) described in the SAR. These simulations provide bounding estimates or predictions of the maximum fuel assembly effluent temperature during each transient The predicted temperatures are then compared to acceptance criteria, which are based on the Flow Instability (FI) limit.

Several types of reactor physics parameters (such as power distribution peaking factors, reactivity addition rates, temperature coefficients of reactivity, and safety rod reactivity worths) are key inputs to the safety analysis calculations. Physics parameters used in the simulation of each DBE are generated for a range of different initial (pre-accident) control rod configurations, as-built core compositions (including variations in moderator $\mathrm{D}_{2} \mathrm{O}$ content), cycle exposures (i.e., time in the cycle), xenon-135 concentrations, and three-dimensional power distributions. The power distributions are characterized by several descriptive parameters, such as rooftop-ratio (RTR) and radial shape factor (RSF). Bounding sets of physics parameters were used in the safety analysis calculations for each DBE.

Physics parameters were generated for an increased range of RTR values extending from 0.66 to 1.46. Sensitivity analyses were performed to evaluate the impact of the more severe physics data on the safety analysis calculations as a result of extending the RTA range. These sensitivity analyses, which were performed in parallel with the physics analyses, were penformed for operation at $30 \%$ of historical power -- the maximum power level currently allowed based on the Gamma Heating phase of the Loss of Coolant Accident (LOCA-GH).

These sensitivity analyses were limited to the types of transients that are potentially affected by changes in axial power distributions: Control Rod Withdrawal Accidents (Single and Gang, including Soismic) and Single (Partlength) Control Rod Insertion Accident. The sensitivity analyses focused on the Anticipated Transient Without Scram (ATWS) analyses of these events which are the most limiting because of the slower response of the mitigation system. K-Reecto ATWS events are mitigated by the Supplementary Safety System (8SS).

The safety analysis sensitivity calculations demonstrated that the safety analysis acceptance criteria are met even with the more severe physics parameters based on the 0.66-10-1.46 range in ATA values. Thus, these analyses confirmed that the conclusions of the SAR are not affected by the larger APM

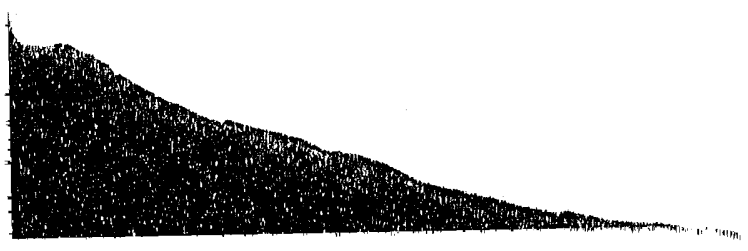


rod uncertainty allowances provided the observed PTR values remain within the Technical Specification limits.

\subsection{OPERATIONAL CONSIDERATIONS}

The Control Computers scan APM sensor data and display the RTR for the operator at the nuclear console. Included in the Control Computer programming is an APM operability check to verify the sensors are responding and the RTR is within a range of 0.5 to 3.0. Changes to this programming will be made to accommodate lower power operation and new APM test data. The first modification will be to set itio minimum allowable sensoi signal to $0.31 \mathrm{mV}$ and begin automatically checking this value when reactor power is $250 \mathrm{MW}$ or. greater. Because ISAL is 270 MW, this reasonableness check will detect a bad sensor (thus an inoperable APM rod) prior to reactor power being raised beyond ISAL and into a power range within which APM operability is required by Technical Specification 3.2.2. Recent test data as discussed in Section 4.0 provides evidence that sensor readings above $0.31 \mathrm{mV}$ have uncertainties which are bounded by the safety analysis. The analog to digital converter scale is also being changed to the $10 \mathrm{mV}$ scale from the $20 \mathrm{mV}$ to be consistent with the expected range of power operation.

In addition, the recent data also indicate a significant bias may exist in the measured RTR for the APM rods in the reactor. A Control Computer program change will be made to allow one bias factor per rod to be entered. Input of the bias factors will be changed through the formal Control Computer change process. In this way the RTR as observed by the operator will be the corrected value. The bias is expected to be flow and power dependent so the factors may have to be changed during the Power Ascension Program.

Historically, the Travelling Wire Flux Monitor (TWFM) was used to calibrate the APMs. A referenced steol wire was remotely inserted into an APM thimble, irradiated for a defined period of time, and then withdrawn past a scimtillation detector. This detector measures the induced activity in the wire. The magnitude of the activity was indicative of the neutron flux that was seen by the wire. Thus the axial profile of the neutron flux can be determined and compared with the APM. With the old APMs, a set of resistors associated with each sensor would be adjusted such that the sensor output would match the reading of the TWFM.

The new APMs do not have the capability to have individual sensor outputs adjusted. Prototypea of the new rods tested in C-Reactor showed excellent agreement with the TWFM's at the power levels of interest at that time. There is limited in-reactor experience with the TWFM's and new APMs at low reactor powers and therefore comparison nus had already been scheduled as part of the Power Ascension Test Program. Due to the recent experimentally determined bias in the ATRs based on cable heating test in K-Reactor, the data obtained from the TWFMPs will be used in conjunction with at-power cable heating tests to determine the appropriate bias factor. 
RTR recorders on the graphic panel receive input directly from the APM sensors (i.e. independent of the Control Computers). Therefore, the RTRs that are displayed on the recorder chart will not be corrected by the bias factor in the Control Computer. The primary pupose of this recorder is to generate an alarm if the RTR drifts outside its required range. In addition, the recorder is observed by the operators during level operation and rod repositioning as a means of confirming the axial power shape is not approaching its limits. The operator also has a Control Computer terminal at the nuclear console which displays the gang average RTRs at all times. Also, a Control Computer program can be initiated at any time which prints out RTRs for all APM rods.

The RTA recorder will continue to be used by the operator to watch for RTR changes but will not be relied upon for absolute values. The Control Computer will be used to obtain the actual RTRs. In addition, modifications to the alarm actuation circuit will be made so that the uperator is warned when the RTR is outside of its specified range.

\subsection{PROCEDURE CHANGES}

Technical Specification 3.2.2 Limiting Condition for Operation (LCO) F requires 7 of 9 APMs to be operable including APM \#1 or \#2, when power is greater than or equal to the Instrument Shape Applicability Limit (ISAL). Surveillance Requirement (SR) 3.2.2.9 requires that testing be pertormed to demonstrate operability of the APMs prior to entry into reactor operation. Performance of testing in accordance with this SR demonstrates that the APMs are responding to simulated signals. This testing is required to be performed prior to entry into reactor operation and monthly during reactor operation. This is currently accomplished through completion of DPSOL-1137A. No modification to DPSOL-1137A is required.

Once the ISAL power level is reached, Technical Specification 3.2.2 LCO G becomes applicable. LCO G requires all operable APMs to have axial power ratios (RTRs) within the limits defined in Table 3.2.2-3. Performance of testing per SR 3.2.2.3 ensures that the conditions of LCO G are mot. Because of the uncertainties associated with the APMs, their output must be at a specified minimum voltage (ensuring instrument accuracy) prior to determining the values required for LCO G. To address this issue, the procedure which implements SR 3.2.2.9. DPSOL-1158, will be modified to check the output voltages of the APMS prior to obtaining the values which determine compliance with Table 3.2.2-3. This check will prevent the use of inaccurate monitors. If the APMs are not respunding at their minimum voltages at ISAL, they must be declared inoperable and the actions required by LCO conditions $F$ and $G$ taken.

During subsequent APM resting per DPSOL-1158 (which is required per SR 3.2.2.3 at a 12 hour frequency), those APMs which had praviously been declared inoperable should have their minimum voltages rechecked. This recheck is necessary because an increase in reactor power should increase the APM output voltage, with the result being APMs which had previously had voltages below the minimum required values now having acceptable voltage 
readings. If this occurs, the formerly inoperable APMs now meet their acceptance criteria arid they should be declared operable.

The Technical Specification as written will adequately ensure APM operability during peactor operation. DPSOL-1158, which ensures the requirenents of SR 3.2.2.3 are met, will be modified to take into account APM Lncertainties at low power and will provide an additional operability check at ISAL and above.

\subsection{STARTUP TEST CHANGES}

\section{Existing}

The following activities related to A.PM performance were scheduled as part of the Startup/Power Ascension Testing program (Reactor Special Procedure (RSP) 90-007) prior to this program assessing APM uncertainty.

\section{- Comparisons of observed/calculated axial power shapes}

These comparisone will be made at proceduraly-specified power levels. For the startup/power ascension lesting. RSP 90-007 directs that no power shaping be done until ISAL, is reached to allow comparisons of observed power shapes with predictions. The RSP requires no power shaping below ISAL to allow predictions for differential rod worths.

\section{- Rocording of the axlal/radial power shapes}

As above, the axial power shapes are provided by the Control Computer from monitoring of signals from the APM rods. Control rod configuration changes would ocour as a result of: 1) power level changes, 2) rod adjustments to change power shape. 3) rod adjusiments to respond to fission product builein/decay/burnup, and 4) control rod adjustments associated with the at-power testing of partial rod worths (RSP 90-007-11 and RSP 90-007-12). The power shape data are intended for post-test analysis aimed towards improving capabilities to predict power shapes for specifiod control rod configurations.

Comperison of APM datm with TWFM date

RSP 90-007 requirea a comparison of APM data with TWFM data for each APM rod so\% por. The implementing procodure is RSP 90-007-14, which requires the two condistent TWPM traces be provided for each APM rod. APM sensor data read from the control computer are compared to digitized dets dorived from the second of the two TWFM traces. A formula woighting esch APM sensor acconding to its importance to the RTR determination is ueed to combine and compare the seneor dente for each rod to the corrosponding TWFM data. ASP 90-0057-14 nequires APM-TWFM agreement of 10\% or better. The TWFM traces are obtained using DPSOL historically used for TWFM operation. 
WSRC-RP-92-594

- APM.DAS

As part of the data-gathering instrumentation for the shutdown tests (RSP 90. $007-15,-17$, and -18 ), a data acquisition system (DAS) that monitors all sensor signals on all APM rods, sampling each signal a minimum of 40 times por second has been installod in K-Reactor. The APM-DAS continuously scans the APM sensors and presents their voltage signal on the terminal screen. The APM-DAS has capability to store about 20 minutes of continuous APM data, being designed to only be used to monitor APM response during a SCRAM or a SSS injection. The APM-DAS may be on-line at any time providing real-time presentation of APM sensor signals, without storing the data. The APM-DAS is situated next to the Power Ascension Data Acquisition System (PADAS) behind the control rod trim panels in the CCR.

\section{Euture}

The following enhancements are being made (and will be in place prior to startup) to RSP 90-007 to expand the amount of APM data and provide options to manipulate the data in real time to provide additional information to operations and test personnel.

-

\section{APM-TWFM callbratlons}

RSP 90-007 is being revised to require pertormance of RSP 90-007-14 ar two specified power levels to provide verification of APM operation prior to attaining power levels at or above ISAL. No additional calibrations havo been specified in RSP 90-007-14, but extensive reviews of the APM and TWFM data by technical personnel will be performed to assess the operational uncertainty of the APM sensors. Assessment of expected TWFM response to irradiation time and reactor power is in progress. TWFM irradiation time has been increased to maintain the total fluence seen by the TWFM wire similar to the fluence at previous operating power lovels.

- APM-DAS

An expansion of the programming of the APM-DAS with the following options has been initiated:

- Provide a corrected sensor reading for each APM sensor of the form

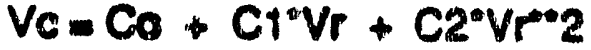

\footnotetext{
where $V_{r}$ is the uncorrected sensor reading, Vc is the corrected sensor

where $\mathrm{Vr}$ is the uncorrecled sensor reading, Vo
reading, and $\mathrm{Co}, \mathrm{C} 1$, and $\mathrm{C2}$ are coefficients.

Allow ontry of the correction coefficients by the user for each sensor and each rod. Coofficients may be derived from APM-TWFM comparisons.

: Provide presentation on terminal of the corrected and uncorrected sensor readings for each sensor in each APM rod.
} 
Provide presentation on terminal of RTR for each APM rod and gang. average RTR using corrected and uncorrected sensor readings.

\subsection{CONCLUSION}

Through the existing internal DOE-contractor processes of review and procedure compliance, a problem with the determination of root-top-ratio was identified. Analyses have been completed to resolve the APM issues described above, and work is progressing to take the needed steps to change operational procedures montrol computer sottware, and the startup test program to assure the RTR urturtainties used in the safety analyses remain valid. The appropriate RTR measuirement uncertainty has been included in the safety analyses, and power ascension can proceed with confidence that the axial power profile can be maintained within acceptable ranges.

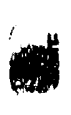



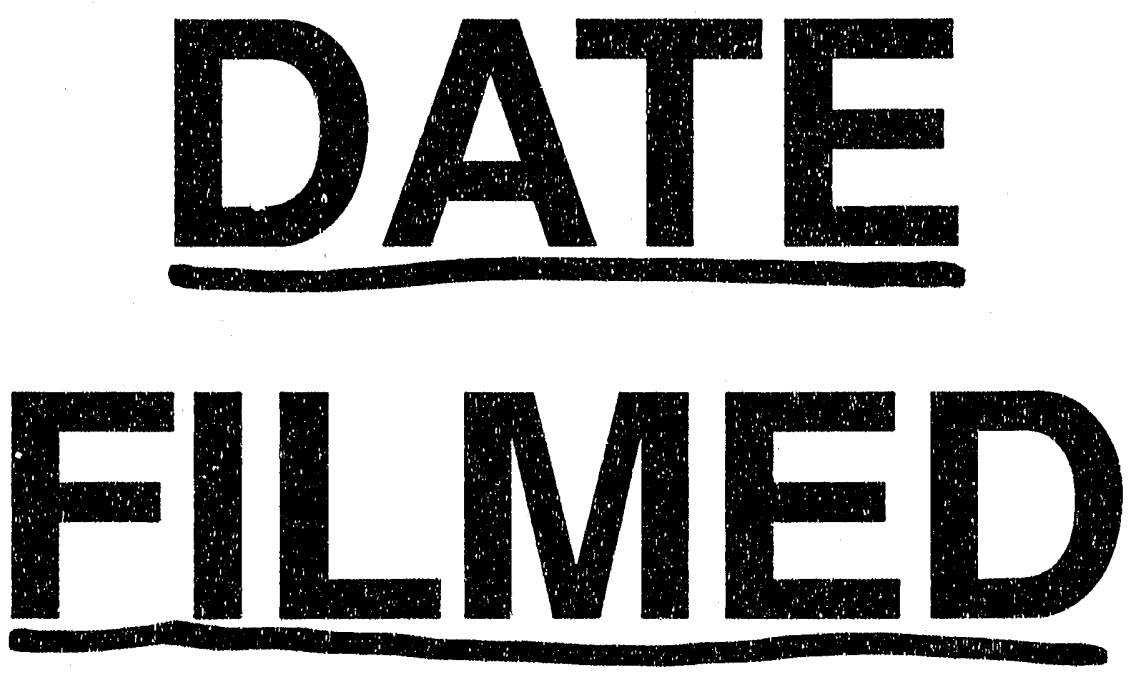

$6 / / 5 / 94$
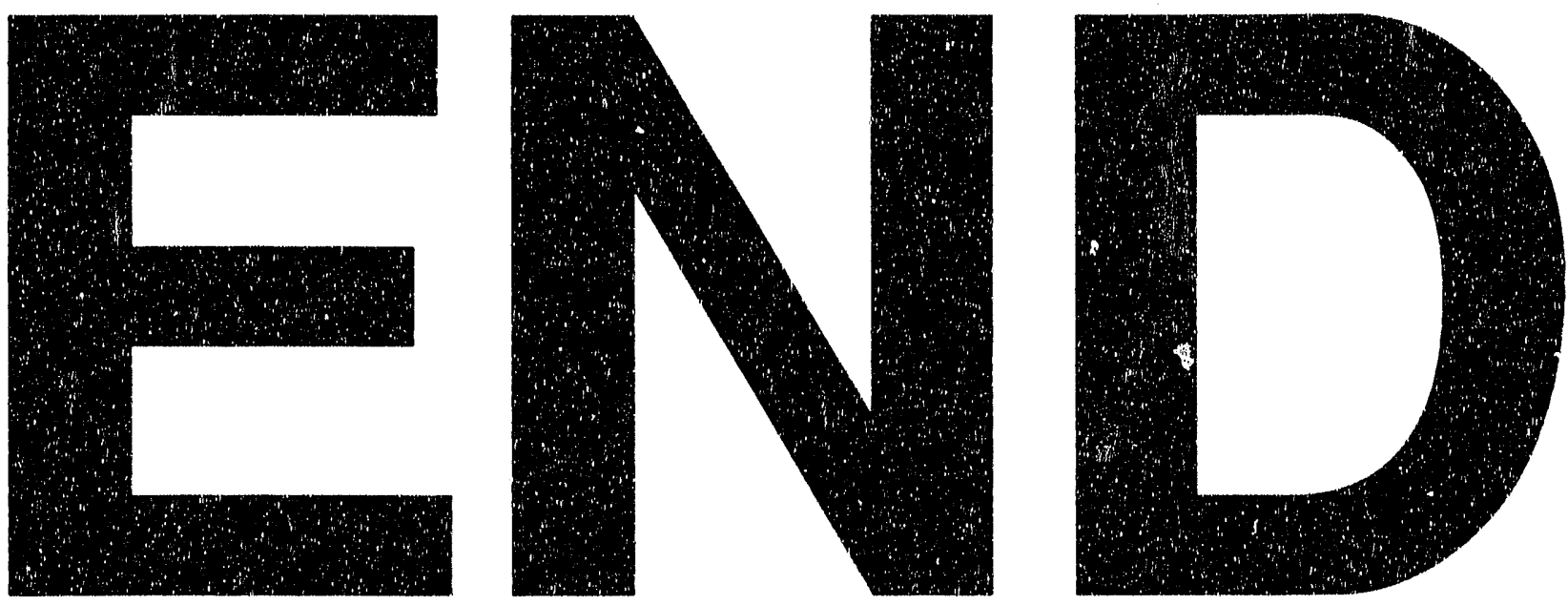

$\overline{1}$ 